Check for updates
OPEN ACCESS

\section{Associations between statins and adverse events in primary prevention of cardiovascular disease: systematic review with pairwise, network, and dose-response meta-analyses}

\author{
Ting Cai, ${ }^{1}$ Lucy Abel, ${ }^{1}$ Oliver Langford, ${ }^{2}$ Genevieve Monaghan,,${ }^{1}$ Jeffrey K Aronson, ${ }^{1}$ \\ Richard J Stevens, ${ }^{1}$ Sarah Lay-Flurrie, ${ }^{1}$ Constantinos Koshiaris, ${ }^{1}$ Richard J McManus, ${ }^{1}$ \\ F D Richard Hobbs, ${ }^{1}$ James P Sheppard ${ }^{1}$
}

${ }^{1}$ Nuffield Department of Primary Care Health Sciences, University of Oxford, Oxford, UK

${ }^{2}$ Alzheimer's Therapeutic Research Institute, University of Southern California, Los Angeles, USA

Correspondence to: J P Sheppard james.sheppard@phc.ox.ac.uk

(or@jamessheppard48 and @tingcai1004 on Twitter ORCID 0000-0002-4461-8756)

Additional material is published online only. To view please visit the journal online.

Cite this as: $B M / 2021 ; 374: n 1537$ http://dx.doi.org/10.1136/bmj.n1537

Accepted: 10 June 2021

\section{ABSTRACT}

OBJECTIVE

To assess the associations between statins and adverse events in primary prevention of cardiovascular disease and to examine how the associations vary by type and dosage of statins.

\section{DESIGN}

Systematic review and meta-analysis.

\section{DATA SOURCES}

Studies were identified from previous systematic reviews and searched in Medline, Embase, and the Cochrane Central Register of Controlled Trials, up to August 2020.

\section{REVIEW METHODS}

Randomised controlled trials in adults without a history of cardiovascular disease that compared statins with non-statin controls or compared different types or dosages of statins were included.

MAIN OUTCOME MEASURES

Primary outcomes were common adverse events: self-reported muscle symptoms, clinically confirmed muscle disorders, liver dysfunction, renal

\section{WHAT IS ALREADY KNOWN ON THIS TOPIC}

Although the efficacy of statins in preventing cardiovascular disease has been well established in previous systematic reviews, their potential adverse effects are inconclusive, particularly for muscle related adverse events, which have been inconsistently defined

The benefit-to-harm balance of statins has been shown to be highly favourable for secondary prevention of cardiovascular disease, but the use of statins in primary prevention is still controversial, owing to the lower risk of cardiovascular disease in this population

Current recommendations on the type and dosage of statins are based on their lipid lowering effects, without considering the varying adverse effects of different regimens

\section{WHAT THIS STUDY ADDS}

Based on data from placebo controlled blinded trials, for primary prevention of cardiovascular disease, a small proportion of self-reported muscle symptoms were attributable to statins, but no evidence of an association between statins and clinically confirmed muscle disorders was found

Adverse events associated with statins were mild and rare, and the absolute increase in the risk of these adverse events did not outweigh the reduction in the risk of major cardiovascular disease events, suggesting that the benefit-to-harm balance of statins for primary prevention of cardiovascular disease is favourable Dose-response relationships between different types of statins and adverse effects were inconclusive, suggesting that tailoring statin regimens to deal with safety concerns when starting treatment is not currently needed insufficiency, diabetes, and eye conditions. Secondary outcomes included myocardial infarction, stroke, and death from cardiovascular disease as measures of efficacy.

\section{DATA SYNTHESIS}

A pairwise meta-analysis was conducted to calculate odds ratios and $95 \%$ confidence intervals for each outcome between statins and non-statin controls, and the absolute risk difference in the number of events per 10000 patients treated for a year was estimated. A network meta-analysis was performed to compare the adverse effects of different types of statins. An $E_{\text {max }}$ model based meta-analysis was used to examine the dose-response relationships of the adverse effects of each statin.

\section{RESULTS}

62 trials were included, with 120456 participants followed up for an average of 3.9 years. Statins were associated with an increased risk of self-reported muscle symptoms (21 trials, odds ratio 1.06 (95\% confidence interval 1.01 to 1.13); absolute risk difference 15 (95\% confidence interval 1 to 29$)$ ), liver dysfunction (21 trials, odds ratio 1.33 (1.12 to 1.58); absolute risk difference 8 (3 to 14)), renal insufficiency (eight trials, odds ratio 1.14 (1.01 to 1.28); absolute risk difference 12 (1 to 24)), and eye conditions (six trials, odds ratio 1.23 (1.04 to 1.47); absolute risk difference 14 (2 to 29)) but were not associated with clinically confirmed muscle disorders or diabetes. The increased risks did not outweigh the reduction in the risk of major cardiovascular events. Atorvastatin, lovastatin, and rosuvastatin were individually associated with some adverse events, but few significant differences were found between types of statins. An $E_{\max }$ dose-response relationship was identified for the effect of atorvastatin on liver dysfunction, but the dose-response relationships for the other statins and adverse effects were inconclusive.

\section{CONCLUSIONS}

For primary prevention of cardiovascular disease, the risk of adverse events attributable to statins was low and did not outweigh their efficacy in preventing cardiovascular disease, suggesting that the benefitto-harm balance of statins is generally favourable. Evidence to support tailoring the type or dosage of statins to account for safety concerns before starting treatment was limited. 


\section{Introduction}

Cardiovascular disease is a leading cause of mortality and morbidity worldwide. ${ }^{1}$ Statins are effective in reducing the risk of cardiovascular disease and have been recommended in clinical guidelines as frontline treatment for the prevention of cardiovascular disease. ${ }^{23}$ Various adverse events have been reported in clinical use, however, including muscle problems, liver dysfunction, renal insufficiency, diabetes, and eye conditions. ${ }^{4}$ Previous studies have shown that uptake and persistence with statin treatment is poor and, as a result, millions of patients could be missing out on life saving treatment. ${ }^{5-8}$ This underuse is partly because of concerns about potential adverse effects, ${ }^{9}$ and these concerns are particularly evident when statins are used for primary prevention in asymptomatic patients without a history of cardiovascular disease. In these individuals, who have a lower average risk of cardiovascular disease, the absolute benefits of statins are smaller than in a secondary prevention population with previous cardiovascular disease events, and therefore the benefit-to-harm balance of treatment might be less favourable. ${ }^{10}$ Nevertheless, recent guidelines have recommended wider use of statins for primary prevention, making a large population at low risk of cardiovascular disease eligible for treatment and exposed to the risks of adverse effects. ${ }^{2} 311$ This increased eligibility for intervention with statins has been controversial, ${ }^{12}$ and better understanding of the risks of adverse effects is needed to determine the trade-off between the benefits and harms of statins in a primary prevention population.

One possible solution to improve the use of statins in primary prevention is to apply a stratified treatment strategy, to target optimal treatments in patients with the best trade-off between benefits and harms. ${ }^{13}$ This strategy could involve tailoring the type and dosage of statins. ${ }^{14}$ Current recommendations on the choice of statin regimen are mainly based on their efficacy in reducing low density lipoprotein cholesterol. ${ }^{23}$ Given the different pharmacological mechanisms by which different statins have beneficial and adverse effects, however, classification of the potencies of different types of statins based on their efficacy alone might not be appropriate when considering the safety of treatment. ${ }^{15} 16$ Understanding the dose-response relationships of adverse effects could help determine the optimal therapeutic dose range of statins for primary prevention, avoiding doses that provide little extra benefit but might cause adverse effects. ${ }^{17} 18$

Most previous systematic reviews of statins focused on efficacy or secondary prevention populations, making it difficult to determine the specific risks of adverse effects in patients without a history of cardiovascular disease. ${ }^{19-21}$ Reviews that examined harms in primary prevention have provided conflicting results, particularly for muscle problems, which were inconsistently defined and involved a wide range of muscle conditions with different severities. ${ }^{22-25}$ In this study, we have systematically reviewed randomised controlled trials in adults without a history of cardiovascular disease, to quantify the associations between statins and adverse events, and to examine how the associations vary by type and dosage of statin. Our aim was to better inform the use of statins in primary prevention of cardiovascular disease.

\section{Methods}

The study was conducted according to the Preferred Reporting Items for Systematic Reviews and MetaAnalyses (PRISMA). ${ }^{26}$ The study protocol was registered on PROSPERO, the international prospective register of systematic reviews (registration No CRD42020169955).

\section{Data sources and search strategies}

To maximise the efficiency of the search, we first identified studies from six large scale systematic reviews of clinical trials of treatment with statins; the most comprehensive systematic review included studies published up to March 2013. ${ }^{19-24}$ To supplement the previous systematic reviews and to identify more recent studies, we searched PubMed/ Medline, Embase (Ovid), and the Cochrane Central Register of Controlled Trials (CENTRAL) for studies published from 1 January 2013 to 1 August 2020. Supplementary table 1 describes the systematic search strategies.

\section{Eligibility criteria and study selection}

Eligible studies were randomised controlled trials in adults (>18 years) without previous cardiovascular events that compared statins with non-statin controls or compared different types or dosages of statins and reported at least one outcome of interest. Nonstatin controls included placebo, usual care, and no treatment. Statin treatments were monotherapy or add-on treatment to usual care or non-drug treatments (eg, diet or exercise). Studies where $70 \%$ or more of the participants had no history of cardiovascular disease were considered eligible to avoid excluding large trials with a small proportion of patients with cardiovascular disease and to limit the loss of information about primary prevention patients. To avoid including early phase trials for mechanistic research, studies that enrolled fewer than 100 participants or lasted for less than four weeks were excluded. Supplementary table 2 provides the full eligibility criteria. Two reviewers (TC and LA) independently selected eligible studies by screening the title and abstract and assessing the full text. Discrepancies were resolved by consensus.

\section{Study outcomes}

The primary outcomes were adverse events that were reported in clinical practice or that came from recent large trials. ${ }^{27-31}$ These adverse events included muscle problems, liver dysfunction, renal insufficiency, diabetes, and eye conditions. To resolve the inconsistent definitions of muscle problems in trials and distinguish their clinical importance, we classified muscle problems as self-reported muscle symptoms and clinically confirmed muscle disorders, and 
examined these two outcomes separately. Self-reported muscle symptoms included myalgia (muscle pain), muscle weakness, and other non-specified muscle discomforts reported by trial participants, without a substantial rise in serum concentration of creatine kinase. Clinically confirmed muscle disorders included a rise in serum concentration of creatine kinase to more than 10 times the upper limit of normal and diagnosed myopathy or rhabdomyolysis, as defined in the original trials. ${ }^{32}$ Liver dysfunction included a rise in serum concentration of aspartate transaminase or alanine transaminase to more than three times the upper limit of normal and other diagnosed liver disorders. ${ }^{33}$ Renal insufficiency included any decline in renal function, the presence of proteinuria, and other diagnosed renal disorders. Diabetes (type 2 diabetes) and eye conditions (cataracts and other eye related conditions) were defined as the diagnoses in the original trials. To compare the potential harms with the benefits of statins in the same population, we also extracted data on three major adverse cardiovascular events as secondary outcomes of efficacy: myocardial infarction, stroke, and death from cardiovascular disease. ${ }^{3435}$

\section{Data extraction and quality assessment}

Extracted data included information on study design, characteristics of participants, allocation of interventions, and outcome measurements. For studies identified from the previous systematic reviews, relevant data were extracted by one reviewer (TC) and checked by another (GM) with a standardised extraction form. Extracted data were also compared with the reported data in the previous reviews to ensure accuracy. For studies identified in database searches, two reviewers (TC and LA) collected the data from each study in duplicate, followed by a cross check of consistency.

The risk of bias in individual studies was assessed with the Cochrane risk of bias tool. ${ }^{36}$ The quality of evidence for each outcome in the pairwise metaanalyses and for any significant results in the network meta-analyses was rated according to the GRADE (Grading of Recommendations Assessment, Development, and Evaluation) process. ${ }^{37} 38$ Two reviewers (TC and LA) independently assessed the risk of bias and the quality of the evidence. Discrepancies were resolved by discussion.

\section{Statistical analysis}

A pairwise meta-analysis was conducted to compare statins with non-statin controls for each primary and secondary outcome. ${ }^{39}$ Heterogeneity among individual studies was assessed with the Q test and quantified with the $\mathrm{I}^{2}$ statistic. ${ }^{40}$ We used a fixed effects model with the Mantel-Haenszel method to calculate pooled odds ratios and 95\% confidence intervals when no significant heterogeneity was detected $(\mathrm{P}>0.05$ for the $\mathrm{Q}$ test and $\mathrm{I}^{2}<50 \%$ ); otherwise, we used a random effects model with the DerSimonian-Laird method. ${ }^{39}$ Absolute risk difference was estimated based on the calculated odds ratio and the overall event rate across the non- statin control groups for each outcome. To compare the absolute risk differences for safety and efficacy outcomes, the event rates derived from different study durations for each outcome were transformed into comparable annual incidences. ${ }^{41}$ Publication bias was examined by the Harbord test of the symmetry of funnel plots when at least 10 studies were involved. Sensitivity analyses, excluding small studies, were performed when publication bias was detected. ${ }^{42}$ The robustness of the pooled results was inspected by leave-one-out influence analysis. ${ }^{43}$ Further sensitivity analyses examined pooled effects with an alternative analysis model to that used in the primary analysis, and by excluding studies that included any patients with cardiovascular disease.

We performed a network meta-analysis by the frequentist method to compare the adverse effects of different types of statins and non-statin controls. ${ }^{44}$ Heterogeneity among individual studies and global inconsistency across different designs of treatment comparisons in the network were assessed with a generalised $Q$ test, based on a fixed effects assumption for heterogeneity and inconsistency. ${ }^{45} \mathrm{~A}$ fixed effects consistency model was used to calculate the pooled odds ratio and 95\% confidence interval for each pair of treatment comparisons. In sensitivity analyses, a random effects consistency model was used to further examine the pooled results. Although a global consistency assumption was adopted, potential local inconsistency between direct and indirect evidence within each treatment comparison was explored by node splitting analysis. ${ }^{46}$

We used a model based meta-analysis method, which fitted the dose specific effects from a network metaanalysis to an $\mathrm{E}_{\max }$ dose-response model, to examine the dose-response relationships of the adverse effects of individual statins. ${ }^{47} 48$ The $\mathrm{E}_{\max }$ model describes pharmacological dose-response relationships with key parameters $\mathrm{E}_{\max }$, the asymptotic maximum drug effect, and $\mathrm{ED}_{50}$, the dose that produces half of the maximum effect. ${ }^{49}$ Posterior means and $95 \%$ credible intervals of the model parameters were estimated with a bayesian approach. ${ }^{47}$

All statistical tests had a two tailed significance level of $\mathrm{P} \leq 0.05$. Analyses were performed with meta, netmeta, and MBNMAdose packages in $\mathrm{R}$ (version 3.6.3).

\section{Patient and public involvement}

This study is part of a wider project examining the benefits and harms of drugs used for the prevention of cardiovascular disease, which was developed with the help of our patient and public adviser. In designing this programme of work, we held two focus groups with 30 older adults to discuss issues related to drugs for the prevention of cardiovascular disease and adverse events, which informed the interpretation of this work. The results of this review will be disseminated to the relevant patient communities.

\section{Results}

Our searches resulted in 7555 potentially relevant citations (308 from previous reviews and 7247 from 
database searches). After removing duplicates, 62 eligible studies were identified by screening of the title and abstract and assessing the full text (fig 1)..$^{303150-109}$ Supplementary table 3 provides a list of studies excluded after assessing the full text, with reasons for exclusion.

\section{Study characteristics}

A total of 120456 participants were enrolled in the included studies and followed up for a mean of 3.9 years. The mean age of all participants was 61 and 48610 (40\%) participants were women. Most studies, except two, enrolled participants with hyperlipidaemia (low density lipoprotein cholesterol $>3 \mathrm{mmol} / \mathrm{L}$ ) or dyslipidaemia, and the common comorbidities in these participants were diabetes (11 studies), asymptomatic atherosclerosis (nine studies), and hypertension (four studies). Twenty studies included some participants with previous cardiovascular disease events, comprising $6 \%$ (7673 participants) of the total number of participants. Thirty eight studies involved a group of non-statin controls, which included placebo (35 studies), usual care (two studies), and no treatment (one study). Seven types of statins were evaluated: atorvastatin (29 studies), fluvastatin (two studies), lovastatin (five studies), pitavastatin (nine studies), pravastatin (21 studies), rosuvastatin (18 studies), and simvastatin (nine studies). The most commonly measured adverse event in these trials was clinically confirmed muscle disorders (42 studies), followed by self-reported muscle symptoms (40 studies) and liver dysfunction (38 studies). Renal insufficiency, diabetes, and eye conditions were reported in fewer studies (16, 10, and six studies, respectively). Table 1 lists the characteristics of the individual studies.

\section{Risk of bias and quality of evidence}

Most of the included studies had a low or unclear risk of bias across all of the domains assessed (fig 2; supplementary fig 1). A few studies were judged to have a high risk of bias for blinding methods, most of which were comparisons between different statin regimens or reported clinically confirmed outcomes. For comparisons between statins and non-statin controls for the risk of self-reported muscle symptoms, which could be more susceptible to bias from blinding, only one small study with usual care control had an unclear risk of bias in blinding ${ }^{103}$ whereas the other 20 studies were placebo controlled trials with a low risk of bias in blinding.

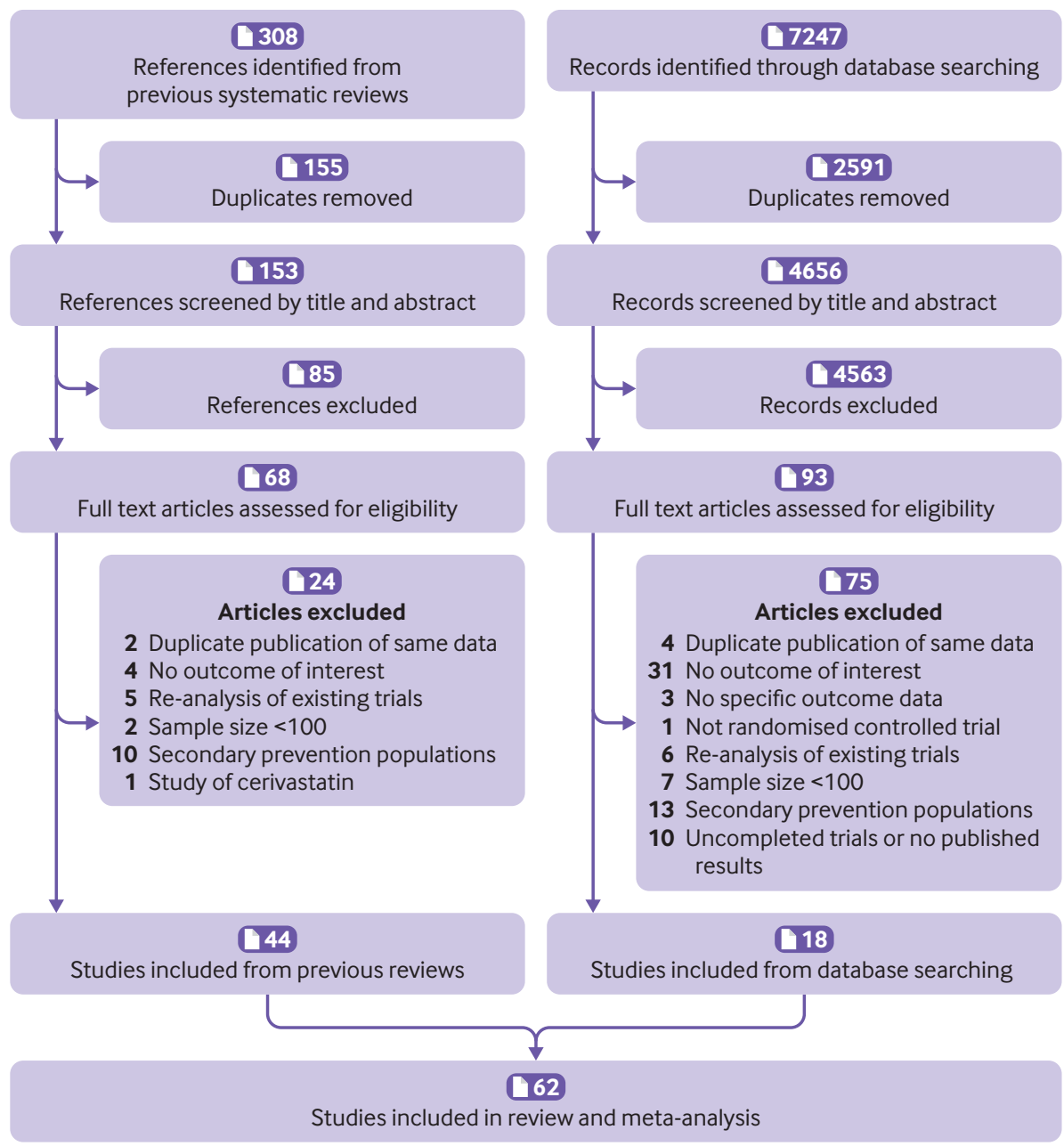

Fig 1 | Flowchart of study selection 
Table 1 | Characteristics of included studies

\begin{tabular}{|c|c|c|c|c|c|c|c|}
\hline \multirow[b]{2}{*}{ Study, year } & \multirow[b]{2}{*}{$\begin{array}{l}\text { No of } \\
\text { participants }\end{array}$} & \multirow[b]{2}{*}{$\begin{array}{l}\text { Study } \\
\text { duration }\end{array}$} & \multicolumn{3}{|l|}{ Study population } & \multirow[b]{2}{*}{ Statin treatment (dose, $\mathrm{mg} /$ day) } & \multirow[b]{2}{*}{ Comparator } \\
\hline & & & $\begin{array}{l}\text { Comorbidities with } \\
\text { hyperlipidaemia or } \\
\text { dyslipidaemia }\end{array}$ & $\begin{array}{l}\text { Mean } \\
\text { age }\end{array}$ & $\begin{array}{l}\text { No (\%) of } \\
\text { women }\end{array}$ & & \\
\hline EXCEL, $1991^{50}$ & 8245 & 1 year & None & 56 & $3380(41)$ & Lovastatin $(20 / 40 / 80)$ & $\begin{array}{l}\text { Placebo, different } \\
\text { statin doses }\end{array}$ \\
\hline ACAPS, $1994^{51}$ & 919 & 3 years & Carotid atherosclerosis & 62 & $441(48)$ & Lovastatin (20) & Placebo \\
\hline PMSG-D, $1994^{52}$ & 325 & 4 months & Diabetes & 58 & $159(49)$ & Pravastatin (10) & Placebo \\
\hline Jacobsen et al, $1995^{53}$ & 245 & 3 months & None & 57 & $76(31)$ & Pravastatin (20) & Placebo \\
\hline KAPS, $1995^{54}$ & 447 & 3 years & None & 57 & $0(0)$ & Pravastatin (40) & Placebo \\
\hline WOSCOPS, $1995^{55}$ & 6595 & 5 years & None & 55 & $0(0)$ & Pravastatin (40) & Placebo \\
\hline CAIUS, $1996^{56}$ & 305 & 3 years & Carotid atherosclerosis & 55 & $143(47)$ & Pravastatin (40) & Placebo \\
\hline Bertolini et al, $1997^{57}$ & 305 & 1.1 years & None & 56 & $168(55)$ & Atorvastatin (10), pravastatin (20) & Different statin types \\
\hline AFCAPS/TexCAPS, $1998^{58}$ & 6605 & 5.2 years & None & 58 & 991 (15) & Lovastatin (20) & Placebo \\
\hline Bak et al, $1998^{59}$ & 215 & 6 months & None & 54 & $0(0)$ & Pravastatin (20) & Placebo \\
\hline Gentile et al, $2000^{60}$ & 409 & 6 months & Diabetes & 59 & $131(32)$ & $\begin{array}{l}\text { Atorvastatin (10), lovastatin (20), } \\
\text { pravastatin (20), simvastatin (10) }\end{array}$ & $\begin{array}{l}\text { Placebo, different } \\
\text { statin types }\end{array}$ \\
\hline ALLHAT-LLT, $2002^{61}$ & 10355 & 4.8 years & Hypertension & 66 & $5074(49)$ & Pravastatin (40) & Usual care \\
\hline ALERT, $2003^{62}$ & 2102 & 5.1 years & Renal transplantation & 50 & $715(34)$ & Fluvastatin (40) & Placebo \\
\hline ASCOT-LLA, $2003^{63}$ & 10305 & 3.3 years & Hypertension & 63 & 1958 (19) & Atorvastatin (10) & Placebo \\
\hline ESG-L, 2003 & 548 & 3 months & None & 56 & $318(58)$ & Lovastatin (10) & Placebo \\
\hline ESG-P, $2003^{65}$ & 538 & 3 months & None & 55 & $301(56)$ & Pravastatin (10) & Placebo \\
\hline Mohler et al, $2003^{66}$ & 354 & 1 year & Peripheral arterial disease & 68 & $81(23)$ & Atorvastatin (10/80) & $\begin{array}{l}\text { Placebo, different } \\
\text { statin doses }\end{array}$ \\
\hline STELLAR, $2003^{67}$ & 2431 & 1.5 months & None & 58 & $1240(51)$ & $\begin{array}{l}\text { Atorvastatin }(10 / 20 / 40 / 80) \text {, pravastatin } \\
(10 / 20 / 40) \text {, rosuvastatin }(10 / 20 / 40 / 80) \text {, } \\
\text { simvastatin }(10 / 20 / 40 / 80)\end{array}$ & $\begin{array}{l}\text { Different statin types } \\
\text { and doses }\end{array}$ \\
\hline CARDS, $2004^{68}$ & 2838 & 3.9 years & Diabetes & 62 & $908(32)$ & Atorvastatin (10) & Placebo \\
\hline DISCOVERY, $2004^{69}$ & 1024 & 3 months & None & 61 & $461(45)$ & Atorvastatin (10), rosuvastatin (10) & Different statin types \\
\hline ESG-S, $2004^{70}$ & 1528 & 3 months & None & 56 & $795(52)$ & Simvastatin (10) & Placebo \\
\hline Muldoon et al, $2004^{71}$ & 308 & 6 months & None & 54 & $160(52)$ & Simvastatin (10/40) & $\begin{array}{l}\text { Placebo, different } \\
\text { statin doses }\end{array}$ \\
\hline PHYLLIS, $2004^{72}$ & 508 & 2.6 years & $\begin{array}{l}\text { Hypertension, carotid } \\
\text { atherosclerosis }\end{array}$ & 58 & $305(60)$ & Pravastatin (40) & Placebo \\
\hline PREVEND-IT, $2004^{73}$ & 864 & 3.8 years & Microalbuminuria & 51 & $302(35)$ & Pravastatin (40) & Placebo \\
\hline BELLES, $2005^{74}$ & 614 & 1 year & None & 64 & $614(100)$ & Atorvastatin (80), pravastatin (40) & Different statin types \\
\hline COMETS, $2005^{75}$ & 396 & 1.5 months & Metabolic syndrome & 58 & $143(36)$ & Atorvastatin (10), rosuvastatin (10) & $\begin{array}{l}\text { Placebo, different } \\
\text { statin types }\end{array}$ \\
\hline CORALL, $2005^{76}$ & 263 & 4.5 months & Diabetes & 60 & $142(54)$ & Atorvastatin (20), rosuvastatin (10) & Different statin types \\
\hline HYRIM, $2005^{77}$ & 568 & 4 years & Hypertension & 57 & $0(0)$ & Fluvastatin (40) & Placebo \\
\hline URANUS, $2005^{78}$ & 469 & 4 months & Diabetes & 64 & $202(43)$ & Atorvastatin (10), rosuvastatin (10) & Different statin types \\
\hline ARIES, $2006^{79}$ & 774 & 1.5 months & None & 55 & $503(65)$ & Atorvastatin $(10 / 20)$, rosuvastatin $(10 / 20)$ & $\begin{array}{l}\text { Different statin types } \\
\text { and doses }\end{array}$ \\
\hline ASPEN-Primary, $2006^{80}$ & 1905 & 4 years & Diabetes & 61 & $724(38)$ & Atorvastatin (10) & Placebo \\
\hline ATOROS, $2006^{81}$ & 120 & 6 months & None & 53 & $53(44)$ & Atorvastatin (20), rosuvastatin (10) & Different statin types \\
\hline MEGA, $2006^{82}$ & 7832 & 5.3 years & None & 58 & $5326(68)$ & Pravastatin (10) & No treatment \\
\hline Schmermund et al, $2006^{83}$ & 467 & 1 year & Coronary atherosclerosis & 62 & $276(59)$ & Atorvastatin $(10 / 80)$ & Different statin doses \\
\hline ANDROMEDA, $2007^{84}$ & 509 & 4 months & Diabetes & 62 & $199(39)$ & Atorvastatin (10), rosuvastatin (10) & Different statin types \\
\hline Bone et al, $2007^{85}$ & 604 & 1.1 years & None & 59 & $604(100)$ & Atorvastatin $(10 / 20 / 40 / 80)$ & $\begin{array}{l}\text { Placebo, different } \\
\text { statin doses }\end{array}$ \\
\hline Lewis et al, $2007^{86}$ & 326 & 9 months & Chronic liver disease & 50 & $156(48)$ & Pravastatin (80) & Placebo \\
\hline METEOR, $2007^{87}$ & 981 & 2 years & Atherosclerosis & 57 & $392(40)$ & Rosuvastatin (40) & Placebo \\
\hline JUPITER, $2008^{30}$ & 17802 & 5 years & Raised $\mathrm{C}$ reactive protein & 66 & $6765(38)$ & Rosuvastatin (20) & Placebo \\
\hline RCASS, $2009^{88}$ & 227 & 2 years & Cerebral atherosclerosis & 63 & $152(67)$ & Simvastatin (20) & Placebo \\
\hline ASTRONOMER, $2010^{89}$ & 269 & 3.5 years & Aortic stenosis & 58 & $102(38)$ & Rosuvastatin (40) & Placebo \\
\hline Eriksson et al, $2011^{90}$ & 352 & 3 months & None & 60 & $113(32)$ & Pitavastatin (4), simvastatin (40) & Different statin types \\
\hline PATROL, $2011^{91}$ & 302 & 4 months & None & 62 & $196(65)$ & $\begin{array}{l}\text { Atorvastatin (10), pitavastatin (2), } \\
\text { rosuvastatin }(2.5)\end{array}$ & Different statin types \\
\hline Ghia et al, $2013^{92}$ & 119 & 3 months & None & 54 & $51(43)$ & Atorvastatin $(10 / 20)$ & Different statin doses \\
\hline Stender et al, $2013^{93}$ & 942 & 3 months & None & 70 & $528(56)$ & $\begin{array}{l}\text { Pitavastatin (1/2/4), pravastatin } \\
(10 / 20 / 40)\end{array}$ & $\begin{array}{l}\text { Different statin types } \\
\text { and doses }\end{array}$ \\
\hline STOMP, $2013^{94}$ & 420 & 6 months & None $^{\star}$ & 44 & $214(51)$ & Atorvastatin (80) & Placebo \\
\hline J-PREDICT, $2014^{95}$ & 1269 & 5 years & $\begin{array}{l}\text { Impaired glucose } \\
\text { tolerance* }\end{array}$ & 56 & $482(38)$ & Pitavastatin (1) & Placebo \\
\hline LISTEN, $2014^{96}$ & 1018 & 1 year & Concurrent diabetes & 66 & $550(54)$ & Atorvastatin (10), rosuvastatin (5) & Different statin types \\
\hline Sponseller et al, $2014^{97}$ & 328 & 3 months & None & 58 & $164(50)$ & Pitavastatin (4), pravastatin (40) & Different statin types \\
\hline Nakagomi et al, $2015^{98}$ & 146 & 1 year & None & 66 & $69(47)$ & Atorvastatin (5), pitavastatin (1) & Different statin types \\
\hline HOPE-3, $2016^{31}$ & 12705 & 5.6 years & None & 66 & $5844(46)$ & Rosuvastatin (10) & Placebo \\
\hline Patil et al, $2016^{99}$ & 100 & 2 months & None & 60 & $49(49)$ & Atorvastatin (20), pitavastatin (4) & Different statin types \\
\hline
\end{tabular}




\begin{tabular}{|c|c|c|c|c|c|c|c|}
\hline \multirow[b]{2}{*}{ Study, year } & \multirow[b]{2}{*}{$\begin{array}{l}\text { No of } \\
\text { participants }\end{array}$} & \multirow[b]{2}{*}{$\begin{array}{l}\text { Study } \\
\text { duration }\end{array}$} & \multicolumn{3}{|l|}{ Study population } & \multirow[b]{2}{*}{ Statin treatment (dose, mg/day) } & \multirow[b]{2}{*}{ Comparator } \\
\hline & & & $\begin{array}{l}\text { Comorbidities with } \\
\text { hyperlipidaemia or } \\
\text { dyslipidaemia }\end{array}$ & $\begin{array}{l}\text { Mean } \\
\text { age }\end{array}$ & $\begin{array}{l}\text { No (\%) of } \\
\text { women }\end{array}$ & & \\
\hline Chen et al, $2018^{100}$ & 180 & 6 months & Cerebral atherosclerosis & 61 & $81(45)$ & $\begin{array}{l}\text { Atorvastatin (20), pravastatin (20), } \\
\text { rosuvastatin (10), simvastatin (40) }\end{array}$ & Different statin types \\
\hline EMPATHY, $2018^{101}$ & 5042 & 5 years & Diabetic retinopathy & 63 & $2622(52)$ & Atorvastatin $(7.6 / 13.1) \dagger$ & Different statin doses \\
\hline INTREPID, $2018^{102}$ & 252 & 1.1 years & HIV infection & 50 & $35(14)$ & Pitavastatin (4), pravastatin (40) & Different statin types \\
\hline Liu et al, $2018^{103}$ & 180 & 6 months & Atherosclerosis & 51 & $81(45)$ & $\begin{array}{l}\text { Atorvastatin (20), pravastatin (20), } \\
\text { simvastatin (20) }\end{array}$ & $\begin{array}{l}\text { Usual care, different } \\
\text { statin types }\end{array}$ \\
\hline BALANCE, $2019^{104}$ & 193 & 6 months & Diabetes & 56 & $97(50)$ & Rosuvastatin (5) & Placebo \\
\hline METEOR-China, $2019^{105}$ & 540 & 2 years & Atherosclerosis & 60 & $302(56)$ & Rosuvastatin (20) & Placebo \\
\hline Peng et al, $2019^{106}$ & 150 & 1 year & $\begin{array}{l}\text { Renal artery } \\
\text { atherosclerosis }\end{array}$ & 64 & $57(38)$ & Rosuvastatin (5/10) & Different statin doses \\
\hline TRACE RA, $2019^{107}$ & 3002 & 5 years & Rheumatoid arthritis & 61 & $2221(74)$ & Atorvastatin (40) & Placebo \\
\hline Moroi et al, $2020^{108}$ & 622 & 5 years & None & 65 & $286(46)$ & Atorvastatin (10), pitavastatin (2) & Different statin types \\
\hline Thongtang et al, $2020^{109}$ & 150 & 3 months & Diabetes & 59 & $108(72)$ & Atorvastatin (40), simvastatin (20) & Different statin types \\
\hline
\end{tabular}

The quality of evidence for comparisons between statins and non-statin controls for self-reported muscle symptoms, liver dysfunction, and the three major cardiovascular events was rated as high, with evidence for the remaining outcomes rated as moderate (table 2). In network meta-analyses, the quality of evidence for individual adverse effects of some types of statins was rated as high or moderate, whereas the quality of evidence for differences between statins was low (supplementary table 4).

\section{Associations of statins with adverse events}

Thirty eight studies that compared statins with nonstatin controls were included in the pairwise metaanalyses. We found no significant heterogeneity between individual studies and used a fixed effects model for all outcomes, with the exception of diabetes where a random effects model was used because significant heterogeneity ( $\mathrm{P}=0.04 ; \mathrm{I}^{2}=50 \% ; 95 \%$ confidence interval $0 \%$ to $77 \%$ ) was detected (fig 3 and supplementary fig 2).

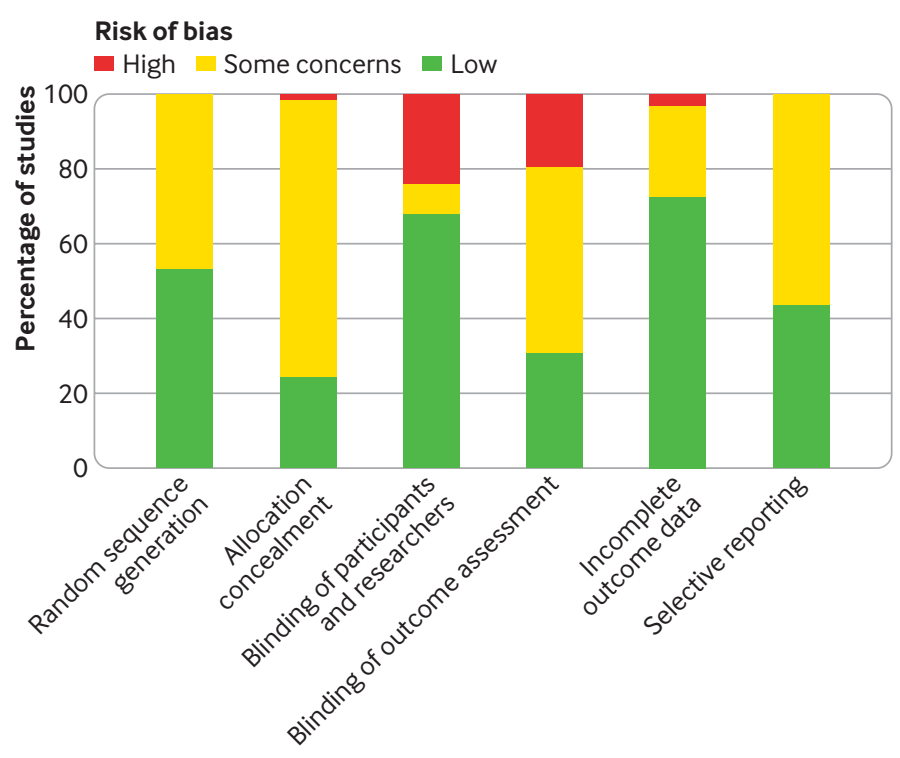

Fig 2 | Summary of risk of bias across all included studies
Statins were associated with a slightly increased risk of self-reported muscle symptoms (21 studies, odds ratio 1.06 (95\% confidence interval 1.01 to 1.13 ); $\mathrm{I}^{2}=1 \%$ (95\% confidence interval $0 \%$ to $47 \%$ ); fig 3), which mainly included myalgia (16 studies). But we found no association between statins and clinically confirmed muscle disorders. The influence analyses (supplementary fig 3) showed that the association between statins and muscle symptoms was largely determined by the double blind, placebo controlled HOPE-3 (Heart Outcomes Prevention Evaluation-3) trial, ${ }^{31}$ whereas the usual care controlled trial had little influence on the pooled result. ${ }^{103}$ Similarly, the no treatment controlled MEGA study (primary prevention of cardiovascular disease with pravastatin in Japan) had no influence on the association with muscle disorders. ${ }^{82}$

Statins increased the risk of liver dysfunction (21 studies, odds ratio 1.33 (95\% confidence interval 1.12 to 1.58$) ; \mathrm{I}^{2}=0 \%$ (95\% confidence interval $0 \%$ to $\left.23 \%\right)$ ), which was defined as raised serum concentration of liver enzymes in all studies. Statins were also associated with renal insufficiency (eight studies, odds ratio 1.14 (1.01 to 1.28$) ; \mathrm{I}^{2}=0 \%(0 \%$ to $23 \%)$ ), which included the presence of proteinuria (four studies) and non-specified renal disorders (four studies), and with eye conditions (six studies, odds ratio 1.23 (1.04 to 1.47$)$; $\mathrm{I}^{2}=0 \%(0 \%$ to $36 \%)$ ), which included cataracts (one study) and non-specified eye disorders (five studies) (fig 3). Influence analyses showed that the association with renal insufficiency was primarily determined by the JUPITER (Justification for the Use of Statin in Prevention: An Intervention Trial Evaluating Rosuvastatin) trial, which examined non-specified renal disorders, ${ }^{30}$ and the association with eye conditions was determined by the HOPE- 3 trial, which examined cataracts. ${ }^{31}$

We did not detect significant publication bias for any safety outcome (supplementary fig 4). In sensitivity analyses (supplementary table 5), the pooled results from an alternative meta-analysis model were similar, and we found no substantial changes after excluding 


\begin{tabular}{|c|c|c|c|c|c|c|c|c|c|}
\hline \multirow[b]{3}{*}{$\begin{array}{l}\text { No of participants, } \\
\text { No of RCTs; mean } \\
\text { follow-up }\end{array}$} & \multicolumn{6}{|c|}{ Quality of evidence } & \multicolumn{3}{|l|}{ Summary of findings } \\
\hline & \multirow[b]{2}{*}{ Risk of bias } & \multirow[b]{2}{*}{ Inconsistency } & \multirow[b]{2}{*}{ Indirectness } & \multirow[b]{2}{*}{ Imprecision } & \multirow[b]{2}{*}{$\begin{array}{l}\text { Publication } \\
\text { bias }\end{array}$} & \multirow[b]{2}{*}{$\begin{array}{l}\text { Overall } \\
\text { certainty of } \\
\text { evidence }\end{array}$} & \multirow[b]{2}{*}{$\begin{array}{l}\text { Relative effect (OR } \\
(95 \% \mathrm{CI}))\end{array}$} & \multicolumn{2}{|c|}{$\begin{array}{l}\text { Anticipated absolute effect } \\
\text { (event rate per } 10000 \text { people } \\
\text { throughout mean follow-up) }\end{array}$} \\
\hline & & & & & & & & $\begin{array}{l}\text { Risk with } \\
\text { controls }\end{array}$ & $\begin{array}{l}\text { Risk difference } \\
(95 \% \mathrm{Cl}) \text { with } \\
\text { statins }\end{array}$ \\
\hline \multicolumn{10}{|l|}{ Muscle symptoms } \\
\hline 65304,$21 ; 4.3$ years & Not serious & Not serious & Not serious & Not serious & None & $\begin{array}{l}\bigoplus \bigoplus \oplus \bigoplus \\
\text { High }\end{array}$ & 1.06 (1.01 to 1.13$)$ & 951 & 56 (5 to 108$)$ \\
\hline \multicolumn{10}{|l|}{ Muscle disorders } \\
\hline 85740,$25 ; 4.2$ years & Not serious & Not serious & Not serious & Serious* & None & $\begin{array}{l}\oplus \oplus \oplus \bigcirc \\
\text { Moderate }\end{array}$ & $0.88(0.62$ to 1.24$)$ & 14 & $-2(-5$ to 3$)$ \\
\hline \multicolumn{10}{|l|}{ Liver dysfunction } \\
\hline 54803,$21 ; 3.8$ years & Not serious & Not serious & Not serious & Not serious & None & $\begin{array}{l}\bigoplus \bigoplus \bigoplus \bigoplus \\
\text { High }\end{array}$ & $1.33(1.12$ to 1.58$)$ & 92 & 30 (11 to 53$)$ \\
\hline \multicolumn{10}{|l|}{ Renal insufficiency } \\
\hline 32001,$8 ; 4.0$ years & Not serious & Serioust & Not serious & Not serious & None & $\begin{array}{l}\oplus \oplus \oplus \bigcirc \\
\text { Moderate }\end{array}$ & 1.14 (1.01 to 1.28$)$ & 343 & 45 (3 to 93) \\
\hline \multicolumn{10}{|l|}{ Diabetes } \\
\hline 58629,$9 ; 4.9$ years & Not serious & Serious $\ddagger$ & Not serious & Not serious & None & $\begin{array}{l}\oplus \oplus \oplus \bigcirc \\
\text { Moderate }\end{array}$ & 1.01 (0.88 to 1.16$)$ & 396 & $4(-45$ to 59$)$ \\
\hline \multicolumn{10}{|l|}{ Eye conditions } \\
\hline 25328,$6 ; 3.8$ years & Not serious & Serious§ & Not serious & Not serious & None & $\begin{array}{l}\oplus \oplus \oplus \bigcirc \\
\text { Moderate }\end{array}$ & $1.23(1.04$ to 1.47$)$ & 233 & 53 (8 to 105) \\
\hline \multicolumn{10}{|l|}{ Myocardial infarction } \\
\hline 95148,$22 ; 4.4$ years & Not serious & Not serious & Not serious & Not serious & Noneף & $\begin{array}{l}\bigoplus \oplus \oplus \bigoplus \\
\text { High }\end{array}$ & $0.72(0.66$ to 0.78$)$ & 292 & $-81(-98$ to -63$)$ \\
\hline \multicolumn{10}{|l|}{ Stroke } \\
\hline 78473,$17 ; 4.7$ years & Not serious & Not serious & Not serious & Not serious & None & $\begin{array}{l}\bigoplus \bigoplus \bigoplus \bigoplus \\
\text { High }\end{array}$ & $0.80(0.72$ to 0.89$)$ & 201 & $-39(-55$ to -22$)$ \\
\hline \multicolumn{10}{|c|}{ Death from cardiovascular disease } \\
\hline 95959,$22 ; 4.4$ years & Not serious & Not serious & Not serious & Not serious & None & $\begin{array}{l}\bigoplus \oplus \oplus \oplus \\
\text { High }\end{array}$ & $0.83(0.76$ to 0.91$)$ & 218 & $-36(-52$ to -19$)$ \\
\hline
\end{tabular}

$\mathrm{RCT}=$ randomised controlled trial; $\mathrm{OR}=\mathrm{odds}$ ratio; GRADE=Grading of Recommendations Assessment, Development, and Evaluation.

*The analysis was underpowered to detect a difference between groups, given the low incidences in both groups.

tFour studies reported the presence of proteinuria although the other four studies reported non-specific renal insufficiency.

$\neq$ One study was conducted in patients with impaired glucose tolerance, which resulted in statistically significant $(P=0.04)$ heterogeneity among the included studies.

$\S 0 n e$ study reported cataracts, one reported diminished visual acuity, one reported eye inflammation, two reported non-specific eye and adnexa disorders, and one reported a combination of different eye conditions.

IPublication bias was detected by examining the asymmetry of the funnel plot for the pairwise meta-analysis of myocardial infarction, but the pooled results did not change after excluding the small studies that caused the detected bias.

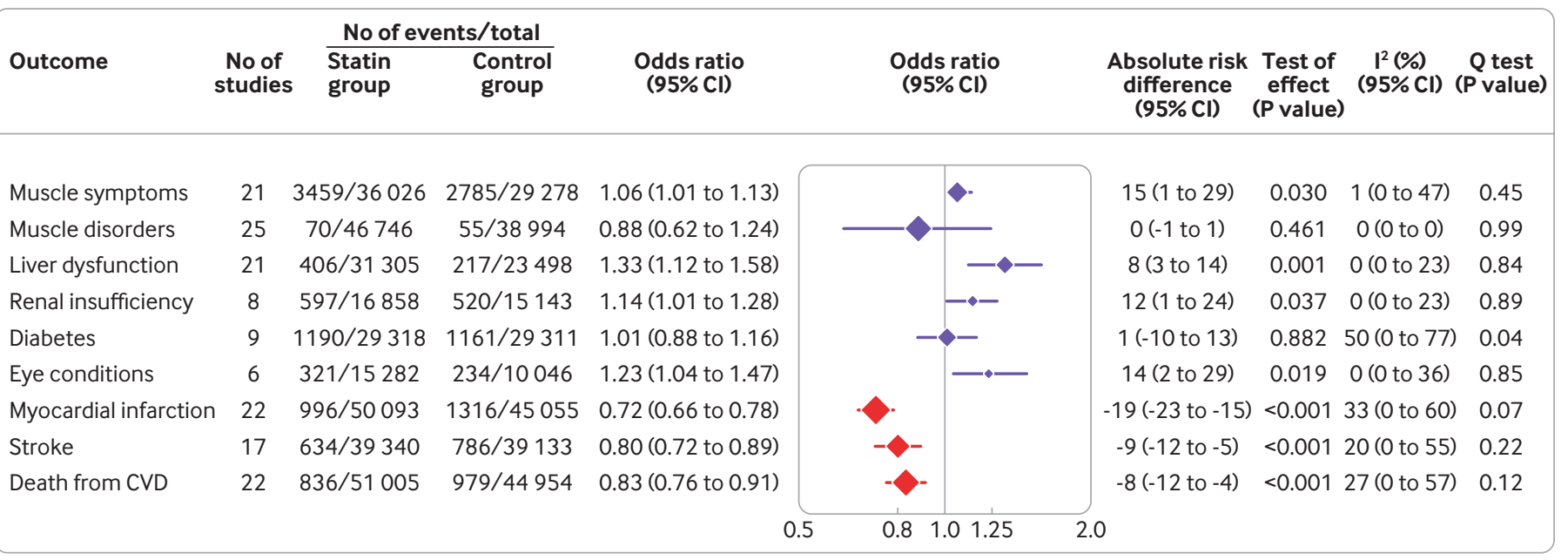

Fig 3 | Associations of statins with safety and efficacy outcomes from pairwise meta-analyses. Symbols and horizontal bars represent pooled odds ratios with $95 \%$ confidence intervals calculated by pairwise meta-analyses, comparing statins and non-statin controls. Symbol sizes are proportional to the total numbers of participants included in the analyses of each outcome. Vertical line represents the odds ratio value that indicates no association (odds ratio=1). Blue symbols denote effects on safety outcomes (adverse events) and red symbols denote effects on efficacy outcomes (major cardiovascular events). Absolute risk difference is the number of events per 10000 people in a year. CVD=cardiovascular disease 
studies that involved some patients with cardiovascular disease.

Comparison between beneficial and harmful effects of statins

For secondary outcomes of efficacy (fig 3 and supplementary fig 2), statins reduced the risks of myocardial infarction (22 studies, odds ratio 0.72 (95\% confidence interval 0.66 to 0.78 ), $\mathrm{I}^{2}=33 \%$ (95\% confidence interval $0 \%$ to $60 \%$ )), stroke (17 studies, odds ratio 0.80 (0.72 to 0.89$) ; \mathrm{I}^{2}=20 \%$ ( $0 \%$ to $\left.55 \%\right)$ ), and death from cardiovascular disease (22 studies, odds ratio 0.83 (0.76 to 0.91 ); $\mathrm{I}^{2}=27 \%$ ( $\%$ to $\left.57 \%\right)$ ). Influence analyses suggested a larger reduction in risk for myocardial infarction and death from cardiovascular disease when the usual care controlled ALLHAT-LLT study (Antihypertensive and Lipid Lowering Treatment to Prevent Heart Attack Trial-Lipid Lowering Trial component) was excluded (supplementary fig 3). ${ }^{61}$ Publication bias was detected for myocardial infarction $(\mathrm{P}<0.05$ for the test of asymmetry of the funnel plot) but the sensitivity analysis by excluding small studies showed a similar pooled effect (supplementary fig 4 and supplementary table 5).

Statins were estimated to induce 15 (95\% confidence interval 1 to 29) more events of muscle symptoms, eight (3 to 14) more of liver dysfunction, 12 (1 to 24) more of renal insufficiency, and 14 (2 to 29) more of eye conditions per 10000 patients treated for a year (fig 3). In contrast, statins were estimated to prevent 19 (15 to 23) myocardial infarctions, nine (5 to 12 ) strokes, and eight (4 to 12) deaths from cardiovascular disease per 10000 patients treated for a year (table 2 shows the event rates throughout the duration of the trials).

Differences in adverse effects between statin types We included 58 studies to construct the networks of treatment comparisons for each safety outcome (supplementary fig 5). Rosuvastatin was associated with an increased risk of self-reported muscle symptoms (13 studies, odds ratio 1.09; 95\% confidence interval 1.01 to 1.16)), renal insufficiency (11 studies, $1.13 ; 1.00$ to 1.28), diabetes (four studies, $1.14 ; 1.00$ to 1.30 ), and eye conditions (two studies, $1.26 ; 1.04$ to 1.52 ) (fig 4). Atorvastatin (17 studies, $1.41 ; 1.08$ to 1.85 ) and lovastatin (five studies, 1.81 ; 1.23 to 2.66 ) increased the risk of liver dysfunction. For comparisons between the different types of statins, lovastatin showed a higher risk of liver dysfunction than fluvastatin and pravastatin, and atorvastatin and rosuvastatin had a higher risk of diabetes than pitavastatin (supplementary table 6). We found no other significant differences between the types of statins.

We did not detect significant between study heterogeneity or between design inconsistency $(\mathrm{P}>0.05$ for the generalised $\mathrm{Q}$ test) in the networks for any outcome (supplementary table 7), justifying the use of a fixed effects consistency model. Results from a random effects consistency model were similar (supplementary table 8). We found no significant inconsistencies between direct and indirect treatment comparisons in node splitting analyses (supplementary table 9).

\section{Dose-response relationships in adverse effects of statins}

All 62 studies were included in the dose-response metaanalyses. A significant $\mathrm{E}_{\max }$ dose-response relationship was only detected for the effect of atorvastatin on liver dysfunction, with a maximum effect that doubled the risk of liver dysfunction with non-statin controls (maximum odds ratio $\left(\mathrm{OR}_{\max }\right)$ 2.03; 95\% credible interval 1.03 to 12.64 ) (table 3 ). No significant doseresponse relationships were detected for other statins or adverse effects. $\mathrm{E}_{\max }$ models were constructed based on the estimates of dose specific adverse effects of individual statins, which had low precision with wide 95\% credible intervals and were available for only one or two dosages for some statins (supplementary fig 6 shows the $\mathrm{E}_{\text {max }}$ dose-response curves plotted on the dose specific adverse effects).

\section{Discussion}

\section{Principal findings}

In this systematic review of randomised controlled trials, we examined the associations between statins and adverse events in adults without a history of cardiovascular disease. We found a slightly increased risk of self-reported muscle symptoms after treatment with statins but no increased risk of clinically confirmed muscle disorders. Statins were associated with liver dysfunction, renal insufficiency, and eye conditions, but were not associated with diabetes. The absolute increases in the risks of these adverse events were small, and not comparable (numerically or clinically) with the reduction in the risk of major cardiovascular events achieved by treatment with statins.

Analyses by type of statin showed that atorvastatin, lovastatin, and rosuvastatin were associated with some adverse events, but few significant differences were seen between the statins. A possible modest dose-response relationship was identified for the effect of atorvastatin on liver dysfunction, but the pharmacological parameters were imprecise and the shape of the dose-response curve was unclear. The dose-response relationships for the other types of statins and adverse effects were inconclusive.

\section{Comparison with other studies}

Most previous systematic reviews of trials examining statins for primary prevention did not find an association between statins and myalgia, myopathy, or rhabdomyolysis, based on small numbers of included studies and inconsistent definitions of outcomes. ${ }^{22} 23$ A previous review found no association between statins and myalgia or other mild muscle symptoms (eg, muscle weakness and stiffness) but excluded some landmark trials, owing to a constrained study population. ${ }^{25}$ In contrast, a recent review showed an association between statins and overall muscle problems, but the review included a wide range of 


\begin{tabular}{|c|c|c|c|c|c|}
\hline Statin type & $\begin{array}{l}\text { No of } \\
\text { studies }\end{array}$ & $\begin{array}{l}\text { No of } \\
\text { events }\end{array}$ & $\begin{array}{c}\text { No of } \\
\text { participants }\end{array}$ & $\begin{array}{l}\text { Odds ratio } \\
(95 \% \mathrm{Cl})\end{array}$ & $\begin{array}{l}\text { Odds ratio } \\
(95 \% \mathrm{Cl})\end{array}$ \\
\hline \multicolumn{6}{|c|}{ Muscle symptoms } \\
\hline Control & 21 & 2785 & 29278 & & Reference group \\
\hline Atorvastatin & 18 & 340 & 6030 & $\Leftrightarrow-$ & 1.06 (0.90 to 1.26$)$ \\
\hline Fluvastatin & 1 & 526 & 1045 & $\cdots$ & 0.99 (0.83 to 1.17 ) \\
\hline Lovastatin & 3 & 540 & 10298 & $\rightarrow-$ & 1.07 (0.88 to 1.31$)$ \\
\hline Pitavastatin & 7 & 45 & 1627 & -•- & 0.70 (0.44 to 1.12$)$ \\
\hline Pravastatin & 13 & 216 & 5312 & $-\infty$ & 0.99 (0.81 to 1.22 ) \\
\hline Rosuvastatin & 13 & 1996 & 18121 & $\Leftrightarrow$ & 1.09 (1.01 to 1.16$)$ \\
\hline Simvastatin & 4 & 13 & 285 & - & 0.64 (0.31 to 1.32 ) \\
\hline \multicolumn{6}{|c|}{ Muscle disorders } \\
\hline Control & 25 & 55 & 38994 & & Reference group \\
\hline Atorvastatin & 20 & 6 & 12564 & $-\bullet-$ & 0.77 (0.35 to 1.69$)$ \\
\hline Fluvastatin & 2 & 4 & 1328 & & 1.29 (0.32 to 5.24$)$ \\
\hline Lovastatin & 4 & 39 & 10317 & $\longrightarrow-$ & 0.84 (0.52 to 1.36$)$ \\
\hline Pitavastatin & 4 & 1 & 1190 & & 1.09 (0.16 to 7.54$)$ \\
\hline Pravastatin & 13 & 6 & 9738 & 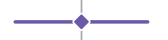 & 0.99 (0.40 to 2.49 ) \\
\hline Rosuvastatin & 13 & 18 & 19171 & $-\bullet-$ & 0.93 (0.50 to 1.75 ) \\
\hline Simvastatin & 5 & 4 & 2153 & & 0.91 (0.28 to 2.99 ) \\
\hline \multicolumn{6}{|c|}{ Liver dysfunction } \\
\hline Control & 21 & 217 & 23498 & & Reference group \\
\hline Atorvastatin & 17 & 140 & 6855 & $-\bullet-$ & 1.41 (1.08 to 1.85$)$ \\
\hline Fluvastatin & 1 & 12 & 1045 & - & 0.71 (0.34 to 1.48 ) \\
\hline Lovastatin & 5 & 165 & 10776 & $-\bullet-$ & 1.81 (1.23 to 2.66$)$ \\
\hline Pitavastatin & 5 & 16 & 1423 & $\longrightarrow$ & 1.04 (0.51 to 2.12 ) \\
\hline Pravastatin & 12 & 69 & 5869 & $\bullet$ & 1.10 (0.71 to 1.41$)$ \\
\hline Rosuvastatin & 11 & 36 & 12124 & $-\bullet$ & 1.39 (0.85 to 2.28$)$ \\
\hline Simvastatin & 6 & 18 & 2256 & & 1.30 (0.52 to 3.21$)$ \\
\hline \multicolumn{6}{|c|}{ Renal insufficiency } \\
\hline Control & 8 & 520 & 15143 & & Reference group \\
\hline Atorvastatin & 9 & 33 & 7130 & $\longrightarrow \bullet$ & 1.23 (0.76 to 1.99$)$ \\
\hline Pitavastatin & 2 & 0 & 334 & & 0.54 (0.04 to 6.44 ) \\
\hline Pravastatin & 3 & 4 & 582 & & 2.03 (0.62 to 6.66$)$ \\
\hline Rosuvastatin & 11 & 563 & 12289 & $\bullet$ & 1.13 (1.00 to 1.28$)$ \\
\hline Simvastatin & 5 & 4 & 2095 & $-\cdot-$ & 1.17 (0.35 to 3.90$)$ \\
\hline \multicolumn{6}{|l|}{ Diabetes } \\
\hline Control & 9 & 1161 & 29311 & & Reference group \\
\hline Atorvastatin & 2 & 159 & 4220 & $-\bullet-$ & 1.14 (0.90 to 1.43 ) \\
\hline Lovastatin & 1 & 72 & 3094 & $-\bullet$ & 0.98 (0.71 to 1.36$)$ \\
\hline Pitavastatin & 2 & 217 & 946 & $-\bullet$ & 0.76 (0.61 to 0.96$)$ \\
\hline Pravastatin & 2 & 247 & 6012 & $-\infty$ & 0.97 (0.81 to 1.16 ) \\
\hline Rosuvastatin & 4 & 504 & 15668 & $\bullet$ & 1.14 (1.00 to 1.30$)$ \\
\hline \multicolumn{6}{|c|}{ Eye conditions } \\
\hline Control & 6 & 234 & 10046 & & Reference group \\
\hline Atorvastatin & 1 & 8 & 1504 & & 1.60 (0.52 to 4.89$)$ \\
\hline Lovastatin & 2 & 43 & 6994 & $\bullet$ & 1.23 (0.60 to 2.53 ) \\
\hline Pravastatin & 1 & 23 & 151 & - & 0.89 (0.47 to 1.67$)$ \\
\hline \multirow[t]{2}{*}{ Rosuvastatin } & 2 & 247 & 6633 & $-\infty$ & 1.26 (1.04 to 1.52$)$ \\
\hline & & & & $\begin{array}{lll}1 & 1 & 1\end{array}$ & \\
\hline
\end{tabular}

Fig 4 | Associations of individual statins with adverse events from network meta-analyses. Symbols and horizontal bars represent pooled odds ratios with $95 \%$ confidence intervals derived from network meta-analyses, comparing individual statins with non-statin controls. Symbol sizes are proportional to the total numbers of participants included in the analyses of each statin type for each outcome. Vertical line represents the odds ratio value that indicates no association (odds ratio $=1$ ) 


\begin{tabular}{|c|c|c|c|c|c|c|}
\hline Statin & Muscle symptoms & Muscle disorders & Liver dysfunction & Renal insufficiency & Diabetes & Eye conditions \\
\hline Atorvastatin & $1.35(0.92$ to 4.46$)$ & 0.89 (0.47 to 1.67$)$ & $2.03(1.03$ to 12.64$)$ & $1.35(0.61$ to 12.83$)$ & $1.18(0.37$ to 4.39$)$ & $1.32(0.36$ to 6.10$)$ \\
\hline Fluvastatin & $1.10(0.61$ to 5.12$)$ & $1.12(0.49$ to 2.79$)$ & $1.02(0.34$ to 33.99$)$ & No data & No data & No data \\
\hline Lovastatin & $1.25(0.79$ to 5.00$)$ & $0.85(0.46$ to 1.46$)$ & $3.29(0.95$ to 40.24$)$ & No data & $0.98(0.14$ to 5.63$)$ & 1.09 (0.38 to 2.83) \\
\hline Pitavastatin & 0.85 (0.43 to 2.01) & $0.94(0.27$ to 2.62$)$ & $1.50(0.41$ to 100.85$)$ & $0.94(0.27$ to 4.70$)$ & $0.74(0.19$ to 3.34$)$ & No data \\
\hline Pravastatin & $1.18(0.79$ to 4.84$)$ & $1.02(0.58$ to 1.76$)$ & $1.13(0.59$ to 14.72$)$ & $1.33(0.60$ to 4.57$)$ & $0.95(0.25$ to 3.77$)$ & 0.91 (0.26 to 3.33) \\
\hline Rosuvastatin & $1.26(0.97$ to 2.82$)$ & $0.92(0.45$ to 1.63$)$ & $1.61(0.75$ to 16.82$)$ & $1.39(0.84$ to 11.03$)$ & $1.16(0.22$ to 4.33$)$ & $1.36(0.56$ to 4.22$)$ \\
\hline Simvastatin & $0.83(0.44$ to 2.58$)$ & $0.94(0.44$ to 2.06$)$ & $1.59(0.60$ to 21.95$)$ & $1.17(0.48$ to 5.20$)$ & No data & No data \\
\hline
\end{tabular}

conditions with varying severities and incidences. ${ }^{24}$ In our review, we searched for more comprehensive data from studies, including those previously omitted, ${ }^{94}$ and classified muscle problems as self-reported symptoms or clinically confirmed disorders, to resolve the inconsistency and variety of definitions of outcomes in trials. This approach allowed us to clarify that statins are associated with a small increased risk of muscle symptoms, but the evidence for muscle disorders in patients with no history of cardiovascular disease was insufficient.

Attributing muscle symptoms to statins was originally identified in observational studies, but this association has been controversial, with some arguing that the higher risk of muscle symptoms in users of statins in routine practice is biased, because patients know they are receiving treatment and they might be aware of the potential adverse effects. ${ }^{110}{ }^{111}$ Our analysis of blinded, placebo controlled trials showed a smaller absolute increased risk of muscle symptoms than that reported in observational studies, supporting the view that most muscle symptoms reported by users of statins are nocebo effects and not actually caused by statins. ${ }^{112}$ An earlier review combining trials in primary and secondary prevention showed a similarly small absolute increased risk of myalgia, which was borderline significant. ${ }^{113}$

For clinically confirmed muscle disorders, previous reviews that included secondary prevention trials detected associations between statins and myopathy and rhabdomyolysis based on larger numbers of participants. ${ }^{114115}$ The analyses were still underpowered, however, given the low incidences of muscle disorders in the statin and control groups, similar to the data in our review.

Our results support the association between statins and liver dysfunction found in previous reviews, and this adverse effect was similar in primary and secondary prevention. ${ }^{24116}$ We also confirmed the associations of statins with renal insufficiency and eye conditions previously reported in primary prevention. ${ }^{23}$ The diagnoses and measurements of these two outcomes in the included trials varied, and our influence analyses suggested that these associations might be limited to non-specific renal disorders and cataracts. In contrast, reviews that included studies in secondary prevention showed inverse or non-significant associations with a reduction in renal function and cataracts. ${ }^{117} 118$ Nevertheless, trial data on specific renal and eye disorders are currently limited in both primary and secondary prevention.

We did not detect an association between statins and diabetes, similar to previous findings in primary prevention populations. $^{2324}$ In a collaborative metaanalysis of secondary prevention trials, however, statins increased the risk of diabetes. ${ }^{119}$ This finding might be because the risk of diabetes is higher in a secondary prevention population or because the review included trials with larger sample sizes, older participants, and statin regimens with higher doses of statins.

Compared with rates seen in routine clinical practice, the baseline incidence of adverse events for patients included in trials might be lower because of differences in patient characteristics. ${ }^{4120}$ These differences could explain the inconsistency seen in the absolute risks of adverse events of treatment with statins between trials and observational studies. Even when estimates from trials and observational studies are taken into account, however, modelling studies suggest that the benefits of statins for primary prevention outweigh their potential harms in most patients eligible for treatment. ${ }^{121}$ In terms of clinical importance, most of the associated adverse events are self-reported, mild, or localised conditions, unlikely to lead to morbidity or mortality, compared with the major cardiovascular events that statins prevent. ${ }^{133112122123}$

Only a few significant effects of individual types of statins were found for specific adverse events in this review (fig 4 and odds ratio values in the results section). The associations of atorvastatin and lovastatin with liver dysfunction could be because these statins are primarily metabolised in the liver. ${ }^{124}$ Rosuvastatin was associated with selfreported muscle symptoms, renal insufficiency, eye conditions, and diabetes, which might be because these risks are limited to rosuvastatin or because of larger sample sizes and higher doses in the trials of rosuvastatin. Comparisons between different types of statins showed considerable uncertainty, owing to insufficient data for several statins, especially fluvastatin, pitavastatin, and simvastatin. The few significant differences between statins could also be because of a false discovery rate potentially caused by the multiple tests conducted in these comparisons. ${ }^{125}$ This uncertainty of differences between statin was also found in previous reviews for primary or secondary prevention. $^{2024}$ 
To our knowledge, a systematic review of the pharmacological dose-response relationships for adverse effects of statins has not been conducted. The only significant dose-response model established in our review suggested that the risk of liver dysfunction increased with increasing doses of atorvastatin. This trend supported the findings in a previous review that compared high dosages of statins with low dosages. ${ }^{116}$ But the estimated parameters in this model were imprecise and could not describe a clear pharmacological dose-response relationship. For other statins and adverse effects, estimates of $E_{\max }$ from the models made it difficult to draw any conclusions about the dose-response relationships. We also obtained $\mathrm{ED}_{50}$ values from these models, but the estimates showed considerable uncertainty and were not clinically relevant (specific results are available from the authors on request). This imprecision and uncertainty might be because of insufficient data on dosages for each statin or because of the low incidence of adverse events across the range of dosages. In the absence of dose-response relationships, a causal relation between statins and muscle symptoms is not well supported. ${ }^{126}$

\section{Strengths and limitations of the study}

This large systematic review examined the association between adverse events and treatment with statins for primary prevention of cardiovascular disease. These analyses looked at the inconsistent reporting of muscle related adverse events in clinical trials and reported the risks of self-reported muscle symptoms and clinically confirmed muscle disorders in primary prevention patients. We used a newly developed method to examine the dose-response relationships of adverse effects of treatment with statins. Compared with other models, the $\mathrm{E}_{\max }$ model reflects the fundamental pharmacodynamics of common inhibitors, such as statins, with clinically interpretable parameters. ${ }^{127}$

Despite these strengths, our review had limitations. Many of the analyses were underpowered to detect differences between groups, owing to the generally low incidence of adverse events and limited sample sizes. Some trials excluded vulnerable individuals more likely to have adverse events (eg, the ALLHAT-LLT trial excluded patients who were known to be intolerant of statins, and the CARDS and METEOR trials excluded patients who had high serum concentrations of creatinine), ${ }^{616887}$ and many had short periods of follow-up (27 of the 62 included trials had a study duration of no more than six months). Therefore, the incidence of adverse events could have been underestimated, and more severe long term adverse events, such as substantial liver injury or renal failure, might have been missed.

Because all of the included studies were primarily designed for evaluation of efficacy, data on adverse events might not have been systematically collected, although not collecting these data is unlikely to have biased the associations found. We transformed the event rates of each outcome throughout the study duration into annual incidences, which might be inaccurate in the absence of time-to-event data. A limitation of the use of study level aggregated data is that potential interactions between individual patient characteristics and effects of treatment cannot be accurately examined, and we had little information on the time of onset or duration of the adverse events, which might be useful for clinical practice. Most of the included trials enrolled patients with hyperlipidaemia or dyslipidaemia, which might not represent the general primary prevention population. Some trials enrolled a small number of patients with cardiovascular disease, although sensitivity analyses excluding these trials had little effect on the overall findings.

\section{Policy implications}

The low risk of adverse events caused by statins reported in this review should reassure patients and physicians that the potential harms of statins are small and should not deter their use for primary prevention of cardiovascular disease. In particular, given the observed benefits of treatment in preventing major cardiovascular events, the slightly increased risk of self-reported muscle symptoms, which have no confirmed effect on physiological function, should not delay starting treatment with statins. For patients who do have muscle symptoms after treatment with statins, these data highlight that, in most cases, the symptoms are unlikely to be caused by treatment with statins alone. Physicians should therefore look at patients' misconceptions of intolerance to statins and perhaps consider providing behavioural interventions, such as n-of- 1 trials, to minimise unnecessary withdrawal of treatment. $^{128129}$

The increased risk of liver dysfunction with statins suggests that routine monitoring of liver function during treatment is probably warranted in primary prevention, as recommended by the manufacturers in the statin product information. The current trial data do not support tailoring the type of statin or dosage to reduce adverse events in patients taking statins for primary prevention of cardiovascular disease.

To help improve adherence to statin treatment, studies are needed to identify patient characteristics that are crucial to these small risks of adverse events, which could be based on individual level data in clinical practice. These studies would also help with more targeted treatment and achieve more efficient monitoring. Future studies might also determine the associations of statins with more severe, long term adverse events, probably with observational and pharmacovigilance data from large populations, which might facilitate the detection of rare adverse events.

\section{Conclusions}

Statins were associated with a small increased risk of self-reported muscle symptoms, liver dysfunction, renal insufficiency, and eye conditions in patients without a history of cardiovascular disease. These adverse effects were mild compared with the potential benefits of treatment with statins in preventing major cardiovascular events, suggesting that the benefit- 
to-harm balance of statins for primary prevention of cardiovascular disease is generally favourable. Evidence that these adverse effects varied by type or dosage of statins was limited, and therefore tailoring statin regimens before starting treatment to deal with concerns about safety is not currently supported.

We thank Nia Roberts, a Bodleian healthcare librarian at the University of Oxford, for her advice on the search strategies used in this review; and Rik van der Veen, a pharmacist and DPhil candidate at the University of Oxford, for his help with resolving the discrepancies in the selection of studies.

Contributors: TC and JPS conceived the study. TC designed the study and wrote the protocol with JPS, SL-F, JKA, RJS, and FDRH. TC developed the search strategies and ran the searches. TC, LA, and GM screened the literature for inclusion, extracted data from included studies, and assessed the quality of individual studies, under the supervision of JPS, SL-F, FDRH, and RJM. TC conducted the pairwise and network meta-analyses, under the supervision of JPS, SL-F, CK, and FDRH. TC conducted the dose-response meta-analyses, with methodology support from OL, under the supervision of JKA and RJS. TC and JPS drafted the manuscript. All authors contributed to critical revision for important intellectual content and approved the final version. JPS is the guarantor for this work and accepts full responsibility for the conduct of the study, had access to the data, and controlled the decision to publish. The corresponding author attests that all listed authors meet authorship criteria and that no others meeting the criteria have been omitted.

Funding: This work was funded by a British Heart Foundation (BHF) PhD Scholarship (FS/19/13/34235) held by TC. JPS and CK are funded by a Wellcome Trust/Royal Society Sir Henry Dale Fellowship (reference 211182/Z/18/Z) held by JPS. JPS also receives funding from a National Institute for Health Research (NIHR) Oxford Biomedical Research Centre (BRC) Senior Fellowship. LA is funded by a Wellcome Trust Doctoral Studentship (reference 217826/Z/19/Z). SL-F is part funded by the NIHR Oxford BRC and the NIHR Applied Research Collaboration (ARC) Oxford and Thames Valley. RJM receives funding from the NIHR ARC Oxford and Thames Valley, the NIHR School for Primary Care Research, and an NIHR senior investigator award. FDRH acknowledges part support from the NIHR ARC Oxford Thames Valley and the NIHR Oxford BRC. The funders were not involved in the design and conduct of the study; collection, management, analysis, and interpretation of the data; preparation, review, or approval of the manuscript; nor the decision to submit the manuscript for publication. The views expressed in this publication are those of the authors and not necessarily those of the BHF, NIHR, or the UK Department of Health and Social Care.

Competing interests: All authors have completed the ICMJE uniform disclosure form at www.icmje.org/coi_disclosure.pdf and declare: authors had financial support from British Heart Foundation, Wellcome Trust, Royal Society, and National Institute for Health Research for the submitted work; no financial relationships with any organisations that might have an interest in the submitted work; IKA has written articles and edited textbooks on adverse drug reactions and has provided reports and testified as an expert witness in cases involving adverse drug reactions, mainly in coroners' courts; there are no other relationships or activities that could appear to have influenced the submitted work.

Ethical approval: Not required.

Data sharing: Requests for data sharing should be sent to the corresponding author (james.sheppard@phc.ox.ac.uk).

JPS affirms that the manuscript is an honest, accurate, and transparent account of the study being reported; that no important aspects of the study have been omitted; and that any discrepancies from the study as originally planned (and, if relevant, registered) have been explained.

Dissemination to participants and related patient and public communities: No participants were included in this work. The findings of this work, including a lay summary of the results, will be make available on the study website: www.phc.ox.ac.uk/research/ stratified-treatments/studies/stratifying-treatments-in-the-multimorbid-frail-elderly-stratify-statins.

Provenance and peer review: Not commissioned; externally peer reviewed.

This is an Open Access article distributed in accordance with the terms of the Creative Commons Attribution (CC BY 4.0) license, which permits others to distribute, remix, adapt and build upon this work, for commercial use, provided the original work is properly cited. See: http://creativecommons.org/licenses/by/4.0/.

1 World Health Organisation. Cardiovascular Diseases. 2021. https:// www.who.int/health-topics/cardiovascular-diseases/\#tab=tab 1.

2 National Institute for Health and Care Excellence. Cardiovascular disease: risk assessment and reduction, including lipid modification (NICE clinical guideline CG181). 2016. https://www.nice.org.uk/ guidance/cg181.

3 Arnett DK, Blumenthal RS, Albert MA, et al. 2019 ACC/AHA Guideline on the Primary Prevention of Cardiovascular Disease: A Report of the American College of Cardiology/American Heart Association Task Force on Clinical Practice Guidelines. I Am Coll Cardiol 2019;74:e177-232. doi:10.1016/j.jacc.2019.03.010

4 Macedo AF, Taylor FC, Casas JP, Adler A, Prieto-Merino D, Ebrahim S. Unintended effects of statins from observational studies in the general population: systematic review and meta-analysis. BMC Med 2014;12:51. doi:10.1186/1741-7015-12-51

5 Matthews A, Herrett E, Gasparrini A, et al. Impact of statin related media coverage on use of statins: interrupted time series analysis with UK primary care data. BMJ 2016;353:i3283. doi:10.1136/bmj. i3283

6 Thompson W, Jarbøl DE, Nielsen JB, Haastrup P, Pottegård A. Statin use and discontinuation in Danes age 70 and older: a nationwide drug utilisation study. Age Ageing 2021;50:554-8. doi:10.1093/ ageing/afaa 160

7 Helin-Salmivaara A, Lavikainen P, Korhonen MJ, et al. Longterm persistence with statin therapy: a nationwide register study in Finland. Clin Ther 2008;30:2228-40. doi:10.1016/j. clinthera.2008.12.003

8 Ryou IS, Chang J, Son JS, et al. Association between CVDs and initiation and adherence to statin treatment in patients with newly diagnosed hypercholesterolaemia: a retrospective cohort study. BM Open 2021;11:e045375. doi:10.1136/bmjopen-2020-045375

9 Yusuf S. Why do people not take life-saving medications? The case of statins. Lancet 2016;388:943-5. doi:10.1016/S01406736(16)31532-X

10 Byrne P, Cullinan J, Smith SM. Statins for primary prevention of cardiovascular disease. BM/ 2019;367:15674. doi:10.1136/bmj.15674

11 McFadden E, Stevens R, Glasziou P, Perera R. Implications of lower risk thresholds for statin treatment in primary prevention: analysis of CPRD and simulation modelling of annual cholesterol monitoring. Prev Med 2015;70:14-6. doi:10.1016/j.ypmed.2014.11.004

12 Abramson JD, Rosenberg HG, Jewell N, Wright JM. Should people at low risk of cardiovascular disease take a statin?BMJ 2013;347:f6123. doi:10.1136/bmi.f6123

13 Trusheim MR, Berndt ER, Douglas FL. Stratified medicine: strategic and economic implications of combining drugs and clinical biomarkers. Nat Rev Drug Discov 2007:6:287-93. doi:10.1038/nrd2251

14 Peck R, Smith P. Beyond Genetics-Stratified and Personalised Medicines Using Multiple Parameters. Pharmaceuticals (Basel) 2010;3:1637-51. doi:10.3390/ph3051637

15 Bellosta S, Paoletti R, Corsini A. Safety of statins: focus on clinical pharmacokinetics and drug interactions. Circulation 2004;109(Suppl 1):III50-7. doi:10.1161/01.CIR.0000131519.15067.1f

16 Iwaki Y, Lee W, Sugiyama Y. Comparative and quantitative assessment on statin efficacy and safety: insights into inter-statin and interindividual variability via dose- and exposure-response relationships. Expert Opin Drug Metab Toxicol 2019;15:897-911. doi:10.1080/17 425255.2019 .1681399

17 Aronson JK, Ferner RE. Joining the DoTS: new approach to classifying adverse drug reactions. BMJ 2003;327:1222-5. doi:10.1136/ bmj.327.7425.1222

18 Dimmitt SB, Stampfer HG, Warren JB. The pharmacodynamic and clinical trial evidence for statin dose. Br J Clin Pharmacol 2018;84:1128-35. doi:10.1111/bcp.13539

19 Alberton M, Wu P, Druyts E, Briel M, Mills EJ. Adverse events associated with individual statin treatments for cardiovascular disease: an indirect comparison meta-analysis. OJM 2012;105:14557. doi:10.1093/qjmed/hcr158

20 Naci H, Brugts J, Ades T. Comparative tolerability and harms of individual statins: a study-level network meta-analysis of 246955 participants from 135 randomized, controlled trials. Circ Cardiovasc Qual Outcomes 2013;6:390-9. doi:10.1161/ CIRCOUTCOMES.111.000071

21 Armitage I, Baigent C, Barnes E, et al, Cholesterol Treatment Trialists Collaboration. Efficacy and safety of statin therapy in older people: a meta-analysis of individual participant data from 28 randomised controlled trials. Lancet 2019;393:407-15. doi:10.1016/S01406736(18)31942-1

22 Taylor F, Huffman MD, Macedo AF, et al. Statins for the primary prevention of cardiovascular disease. Cochrane Database Syst Rev 2013;(1):CD004816. doi:10.1002/14651858.CD004816.pub5 
23 Chou R, Dana T, Blazina I, Daeges M, Jeanne TL. Statins for Prevention of Cardiovascular Disease in Adults: Evidence Report and Systematic Review for the US Preventive Services Task Force. JAMA 2016;316:2008-24. doi:10.1001/jama.2015.15629

24 Yebyo HG, Aschmann HE, Kaufmann M, Puhan MA. Comparative effectiveness and safety of statins as a class and of specific statins for primary prevention of cardiovascular disease: A systematic review, meta-analysis, and network meta-analysis of randomized trials with 94,283 participants. Am Heart J 2019;210:18-28. doi:10.1016/j. ahj.2018.12.007

25 Zhou Z, Albarqouni L, Curtis AJ, Breslin M, Nelson M. The Safety and Tolerability of Statin Therapy in Primary Prevention in Older Adults: A Systematic Review and Meta-analysis. Drugs Aging 2020;37:17585. doi:10.1007/s40266-019-00736-y

26 Moher D, Liberati A, Tetzlaff J, Altman DG, PRISMA Group. Preferred reporting items for systematic reviews and meta-analyses: the PRISMA statement. PLoS Med 2009;6:e1000097. doi:10.1371/ journal.pmed.1000097

27 Cohen JD, Brinton EA, Ito MK, Jacobson TA. Understanding Statin Use in America and Gaps in Patient Education (USAGE): an internetbased survey of 10,138 current and former statin users. J Clin Lipidol 2012:6:208-15. doi:10.1016/j.jacl.2012.03.003

28 Björnsson E, Jacobsen El, Kalaitzakis E. Hepatotoxicity associated with statins: reports of idiosyncratic liver injury post-marketing. J Hepatol 2012;56:374-80. doi:10.1016/i.jhep.2011.07.023

29 Wolfe SM. Dangers of rosuvastatin identified before and after FDA approval. Lancet 2004;363:2189-90. doi:10.1016/S01406736(04)16513-6

30 Ridker PM, Danielson E, Fonseca FAH, et al, JUPITER Study Group. Rosuvastatin to prevent vascular events in men and women with elevated C-reactive protein. N Engl J Med 2008;359:2195-207. doi:10.1056/NEJMoa0807646

31 Yusuf S, Bosch J, Dagenais G, et al, HOPE-3 Investigators. Cholesterol lowering in intermediate-risk persons without cardiovascular disease. N Engl J Med 2016;374:2021-31. doi:10.1056/NEJMoa1600176

32 Stroes ES, Thompson PD, Corsini A, et al, European Atherosclerosis Society Consensus Panel. Statin-associated muscle symptoms: impact on statin therapy-European Atherosclerosis Society Consensus Panel Statement on Assessment, Aetiology and Management. Eur Heart J 2015;36:1012-22. doi:10.1093/ eurheartj/ehv043

33 Bays $\mathrm{H}$, Cohen DE, Chalasani N, Harrison SA, The National Lipid Association's Statin Safety Task Force. An assessment by the Statin Liver Safety Task Force: 2014 update. / Clin Lipidol 2014;8(Suppl):S47-57. doi:10.1016/j.jacl.2014.02.011

34 Akyea RK, Leonardi-Bee J, Asselbergs FW, et al. Predicting major adverse cardiovascular events for secondary prevention: protocol for a systematic review and meta-analysis of risk prediction models. $B M$, Open 2020:10:e034564 doi:10.1136/bmiopen-2019-034564

35 Miao B, Hernandez AV, Alberts MJ, Mangiafico N, Roman YM, Coleman $\mathrm{Cl}$. Incidence and Predictors of Major Adverse Cardiovascular Events in Patients With Established Atherosclerotic Disease or Multiple Risk Factors. J Am Heart Assoc 2020;9:e014402. doi:10.1161/ IAHA.119.014402

36 Higgins JP, Altman DG, Gøtzsche PC, et al, Cochrane Bias Methods Group, Cochrane Statistical Methods Group. The Cochrane Collaboration's tool for assessing risk of bias in randomised trials. BMJ 2011;343:d5928. doi:10.1136/bmj.d5928

37 Schünemann H, Brozek J, Guyatt G, Oxman A. Handbook for grading the quality of evidence and the strength of recommendations using the GRADE approach. 2013. https://gdt.gradepro.org/app/ handbook/handbook.html\#h.svwngs6pmof2.

38 Puhan MA, Schünemann HJ, Murad MH, et al, GRADE Working Group. A GRADE Working Group approach for rating the quality of treatment effect estimates from network meta-analysis. BMJ 2014;349:95630. doi:10.1136/bmj.g5630

39 Higgins J, Thomas J, Chandler J, et al. Cochrane Handbook for Systematic Reviews of Interventions Version 6.1. 2020. https:// training cochrane.org/handbook.

40 Higgins JPT, Thompson SG, Deeks JJ, Altman DG. Measuring inconsistency in meta-analyses. BMJ 2003;327:557-60. doi:10.1136/bmj.327.7414.557

41 Rothman KJ. Epidemiology - An Introduction. Oxford University Press, 2002: 34-6

42 Harbord RM, Egger M, Sterne JA. A modified test for small-study effects in meta-analyses of controlled trials with binary endpoints. Stat Med 2006:25:3443-57. doi:10.1002/sim.2380

43 Viechtbauer W, Cheung MW. Outlier and influence diagnostics for meta-analysis. Res Synth Methods 2010;1:112-25. doi:10.1002 jrsm 11

44 Rücker G. Network meta-analysis, electrical networks and graph theory. Res Synth Methods 2012;3:312-24. doi:10.1002/jrsm.1058

45 Krahn U, Binder H, König J. A graphical tool for locating inconsistency in network meta-analyses. BMC Med Res Methodol 2013;13:35. doi:10.1186/1471-2288-13-35
46 Dias S, Welton NJ, Caldwell DM, Ades AE. Checking consistency in mixed treatment comparison meta-analysis. Stat Med 2010;29:93244. doi:10.1002/sim.3767

47 Mawdsley D, Bennetts M, Dias S, Boucher M, Welton NJ. ModelBased Network Meta-Analysis: A Framework for Evidence Synthesis of Clinical Trial Data. CPT Pharmacometrics Syst Pharmacol 2016;5:393-401. doi:10.1002/psp4.12091

48 Langford O, Aronson JK, van Valkenhoef G, Stevens RJ. Methods for meta-analysis of pharmacodynamic dose-response data with application to multi-arm studies of alogliptin. Stat Methods Med Res 2018;27:564-78. doi:10.1177/0962280216637093

49 Kirby S, Brain P, Jones B. Fitting E(max) models to clinical trial doseresponse data. Pharm Stat 2011:10:143-9 doi:10.1002/pst.432

50 Bradford RH, Shear CL, Chremos AN, et al. Expanded Clinica Evaluation of Lovastatin (EXCEL) study results. I. Efficacy in modifying plasma lipoproteins and adverse event profile in 8245 patients with moderate hypercholesterolemia. Arch Intern Med 1991;151:43-9. doi:10.1001/archinte.1991.00400010067008

51 Furberg CD, Adams HPJr, Applegate WB, et al, Asymptomatic Carotid Artery Progression Study (ACAPS) Research Group. Effect of lovastatin on early carotid atherosclerosis and cardiovascular events. Circulation 1994:90:1679-87. doi:10.1161/01.CIR.90.4.1679

52 Behounek BD, McGovern ME, Kassler-Taub KB, Markowitz JS, Bergman M, Pravastatin Multinational Study Group for Diabetes. A multinational study of the effects of low-dose pravastatin in patients with non-insulin-dependent diabetes mellitus and hypercholesterolemia. Clin Cardiol 1994;17:558-62. doi:10.1002/ clc.4960171009

53 Jacobson TA, Chin MM, Curry CL, et al. Efficacy and safety of pravastatin in African Americans with primary hypercholesterolemia. Arch Intern Med 1995;155:1900-6. doi:10.1001/ archinte.1995.00430170096012

54 Salonen R, Nyyssönen K, Porkkala E, et al. Kuopio Atherosclerosis Prevention Study (KAPS). A population-based primary preventive trial of the effect of LDL lowering on atherosclerotic progression in carotid and femoral arteries. Circulation 1995;92:1758-64. doi:10.1161/01.CIR.92.7.1758

55 Shepherd J, Cobbe SM, Ford I, et al, West of Scotland Coronary Prevention Study Group. Prevention of coronary heart disease with pravastatin in men with hypercholesterolemia. N Engl Med 1995;333:1301-7. doi:10.1056/NEJM199511163332001

56 Mercuri M, Bond MG, Sirtori CR, et al. Pravastatin reduces carotid intima-media thickness progression in an asymptomatic hypercholesterolemic mediterranean population: the Carotid Atherosclerosis Italian Ultrasound Study. Am J Med 1996;101:62734. doi:10.1016/S0002-9343(96)00333-6

57 Bertolini S, Bon GB, Campbell LM, et al. Efficacy and safety of atorvastatin compared to pravastatin in patients with hypercholesterolemia. Atherosclerosis 1997;130:191-7. doi:10.1016/S0021-9150(96)06052-2

58 Downs JR, Clearfield M, Weis S, et al. Primary prevention of acute coronary events with lovastatin in men and women with average cholesterol levels: results of AFCAPS/TexCAPS. Air Force/Texas Coronary Atherosclerosis Prevention Study. JAMA 1998;279:161522. doi:10.1001/jama.279.20.1615

59 Bak AAA, Huizer J, Leijten PA, Rila H, Grobbee DE. Diet and pravastatin in moderate hypercholesterolaemia: a randomized tria in 215 middle-aged men free from cardiovascular disease. J Intern Med 1998;244:371-8. doi:10.1046/j.1365-2796.1998.00350.x

60 Gentile S, Turco S, Guarino G, et al. Comparative efficacy study of atorvastatin vs simvastatin, pravastatin, lovastatin and placebo in type 2 diabetic patients with hypercholesterolaemia. Diabetes Obes Metab 2000;2:355-62. doi:10.1046/j.1463-1326.2000.00106.x

61 Furberg CD, Wright JTJr, Davis BR, et al, ALLHAT Officers and Coordinators for the ALLHAT Collaborative Research Group. The Antihypertensive and Lipid-Lowering Treatment to Prevent Heart Attack Trial. Major outcomes in moderately hypercholesterolemic, hypertensive patients randomized to pravastatin vs usual care: The Antihypertensive and Lipid-Lowering Treatment to Prevent Heart Attack Trial (ALLHAT-LLT) IAMA 2002:288:2998-3007 doi:10.1001/jama.288.23.2998

62 Holdaas H, Fellström B, Jardine AG, et al, Assessment of LEscol in Renal Transplantation (ALERT) Study Investigators. Effect of fluvastatin on cardiac outcomes in renal transplant recipients: a multicentre, randomised, placebo-controlled trial. Lancet 2003;361:2024-31. doi:10.1016/S0140-6736(03)13638-0

63 Sever PS, Dahlöf B, Poulter NR, et al, ASCOT investigators. Prevention of coronary and stroke events with atorvastatin in hypertensive patients who have average or lower-than-average cholesterol concentrations, in the Anglo-Scandinavian Cardiac Outcomes Trial--Lipid Lowering Arm (ASCOT-LLA): a multicentre randomised controlled trial. Lancet 2003;361:1149-58. doi:10.1016/S0140-6736(03)12948-0

64 Kerzner B, Corbelli J, Sharp S, et al, Ezetimibe Study Group. Efficacy and safety of ezetimibe coadministered with lovastatin in primary hypercholesterolemia. Am J Cardiol 2003;91:418-24. doi:10.1016/ S0002-9149(02)03236-8 
65 Melani L, Mills R, Hassman D, et al, Ezetimibe Study Group. Efficacy and safety of ezetimibe coadministered with pravastatin in patients with primary hypercholesterolemia: a prospective, randomized, double-blind trial. Eur Heart J 2003;24:717-28. doi:10.1016/ S0195-668X(02)00803-5

66 Mohler ER3rd, Hiatt WR, Creager MA. Cholesterol reduction with atorvastatin improves walking distance in patients with periphera arterial disease. Circulation 2003;108:1481-6. doi:10.1161/01. CIR.0000090686.57897.F5

67 Jones PH, Davidson MH, Stein EA, et al, STELLAR Study Group. Comparison of the efficacy and safety of rosuvastatin versus atorvastatin, simvastatin, and pravastatin across doses (STELLAR* Trial). Am J Cardiol 2003;92:152-60. doi:10.1016/S0002 9149(03)00530-7

68 Colhoun HM, Betteridge DJ, Durrington PN, et al, CARDS investigators. Primary prevention of cardiovascular disease with atorvastatin in type 2 diabetes in the Collaborative Atorvastatin Diabetes Study (CARDS): multicentre randomised placebo-controlled trial. Lancet 2004:364:685-96. doi:10.1016/S0140-6736(04)16895-5

69 Strandberg TE, Feely J, Sigurdsson EL, DISCOVERY study group. Twelve-week, multicenter, randomized, open-label comparison of the effects of rosuvastatin $10 \mathrm{mg} / \mathrm{d}$ and atorvastatin $10 \mathrm{mg} / \mathrm{d}$ in high-risk adults: a DISCOVERY study. Clin Ther 2004;26:1821-33. doi:10.1016/j.clinthera.2004.11.015

70 Bays HE, Ose L, Fraser N, et al, Ezetimibe Study Group. A multicenter, randomized, double-blind, placebo-controlled, factorial design study to evaluate the lipid-altering efficacy and safety profile of the ezetimibe/simvastatin tablet compared with ezetimibe and simvastatin monotherapy in patients with primary hypercholesterolemia. Clin Ther 2004;26:1758-73. doi:10.1016/j. clinthera.2004.11.016

71 Muldoon MF, Ryan CM, Sereika SM, Flory JD, Manuck SB. Randomized trial of the effects of simvastatin on cognitive functioning in hypercholesterolemic adults. Am J Med 2004;117:823-9. doi:10.1016/j.amjmed.2004.07.041

72 Zanchetti A, Crepaldi G, Bond MG, et al, PHYLLIS Investigators. Different effects of antihypertensive regimens based on fosinopril or hydrochlorothiazide with or without lipid lowering by pravastatin on progression of asymptomatic carotid atherosclerosis: principal results of PHYLLIS--a randomized double-blind trial. Stroke 2004;35:280712. doi:10.1161/01.STR.0000147041.00840.59

73 Asselbergs FW, Diercks GFH, Hillege HL, et al, Prevention of Renal and Vascular Endstage Disease Intervention Trial (PREVEND IT) Investigators. Effects of fosinopril and pravastatin on cardiovascular events in subjects with microalbuminuria. Circulation 2004:110:2809-16. doi:10.1161/01. CIR.0000146378.65439.7A

74 Raggi P, Davidson M, Callister TQ, et al. Aggressive versus moderate lipid-lowering therapy in hypercholesterolemic postmenopausal women: Beyond Endorsed Lipid Lowering with EBT Scanning (BELLES). Circulation 2005;112:563-71. doi:10.1161/ CIRCULATIONAHA.104.512681

75 Stalenhoef AFH, Ballantyne CM, Sarti C, et al. A comparative study with rosuvastatin in subjects with metabolic syndrome: results of the COMETS study. Eur Heart J 2005;26:2664-72. doi:10.1093/ eurheartj/ehi482

76 Wolffenbuttel BHR, Franken AAM, Vincent HH, Dutch Corall Study Group. Cholesterol-lowering effects of rosuvastatin compared with atorvastatin in patients with type 2 diabetes -- CORALL study. J Intern Med 2005;257:531-9. doi:10.1111/j.1365-2796.2005.01499.x

77 Anderssen SA, Hjelstuen AK, Hjermann I, Bjerkan K, Holme I. Fluvastatin and lifestyle modification for reduction of carotid intimamedia thickness and left ventricular mass progression in drug-treated hypertensives. Atherosclerosis 2005;178:387-97. doi:10.1016/j. atherosclerosis.2004.08.033

78 Berne C, Siewert-Delle A, Ekesbo R, et al, URANUS study investigators. Comparison of rosuvastatin and atorvastatin for lipid lowering in patients with type 2 diabetes mellitus: results from the URANUS study. Cardiovasc Diabetol 2005;4:7. doi:10.1186/1475-2840-4-7

79 Ferdinand KC, Clark LT, Watson KE, et al, ARIES Study Group. Comparison of efficacy and safety of rosuvastatin versus atorvastatin in African-American patients in a six-week trial. Am J Cardiol 2006:97:229-35. doi:10.1016/j.amjcard.2005.08.026

80 Knopp RH, d'Emden M, Smilde JG, Pocock SJ. Efficacy and safety of atorvastatin in the prevention of cardiovascular end points in subjects with type 2 diabetes: the Atorvastatin Study for Prevention of Coronary Heart Disease Endpoints in non-insulin-dependent diabetes mellitus (ASPEN). Diabetes Care 2006;29:1478-85. doi:10.2337/dc05-2415

81 Milionis HJ, Rizos E, Kostapanos M, et al. Treating to target patients with primary hyperlipidaemia: comparison of the effects of ATOrvastatin and ROSuvastatin (the ATOROS study). Curr Med Res Opin 2006:22:1123-31. doi:10.1185/030079906X112462

82 Nakamura H, Arakawa K, Itakura H, et al, MEGA Study Group. Primary prevention of cardiovascular disease with pravastatin in Japan
(MEGA Study): a prospective randomised controlled trial. Lancet 2006;368:1155-63. doi:10.1016/S0140-6736(06)69472-5

83 Schmermund A, Achenbach S, Budde T, et al. Effect of intensive versus standard lipid-lowering treatment with atorvastatin on the progression of calcified coronary atherosclerosis over 12 months: a multicenter, randomized, doubleblind trial. Circulation 2006;113:427-37. doi:10.1161/ CIRCULATIONAHA.105.568147

84 Betteridge DJ, Gibson JM. Effects of rosuvastatin on lipids, lipoproteins and apolipoproteins in the dyslipidaemia of diabetes. Diabet Med 2007;24:541-9. doi:10.1111/j.14645491.2007.02095 x

85 Bone HG, Kiel DP, Lindsay RS, et al. Effects of atorvastatin on bone in postmenopausal women with dyslipidemia: a doubleblind, placebo-controlled, dose-ranging trial. / Clin Endocrinol Metab 2007:92:4671-7. doi:10.1210/jc.2006-1909

86 Lewis JH, Mortensen ME, Zweig S, Fusco MJ, Medoff JR, Belder R, Pravastatin in Chronic Liver Disease Study Investigators. Efficacy and safety of high-dose pravastatin in hypercholesterolemic patients with well-compensated chronic liver disease: Results of a prospective, randomized, double-blind, placebo-controlled, multicenter trial. Hepatology 2007;46:1453-63. doi:10.1002/hep.21848

87 Crouse JR3rd, Raichlen JS, Riley WA, et al, METEOR Study Group. Effect of rosuvastatin on progression of carotid intima-media thickness in low-risk individuals with subclinical atherosclerosis: the METEOR Trial. JAMA 2007;297:1344-53. doi:10.1001/jama.297.12.1344

88 Mok VCT, Lam WWM, Chen XY, et al. Statins for asymptomatic middle cerebral artery stenosis: The Regression of Cerebral Artery Stenosis study. Cerebrovasc Dis 2009;28:18-25. doi:10.1159/000215939

89 Chan KL, Teo K, Dumesnil JG, Ni A, Tam JASTRONOMER Investigators. Effect of Lipid lowering with rosuvastatin on progression of aortic stenosis: results of the aortic stenosis progression observation: measuring effects of rosuvastatin (ASTRONOMER) trial. Circulation 2010;121:306-14. doi:10.1161/ CIRCULATIONAHA.109.900027

90 Eriksson M, Budinski D, Hounslow N. Comparative efficacy of pitavastatin and simvastatin in high-risk patients: a randomized controlled trial. Adv Ther 2011;28:811-23. doi:10.1007/s12325011-0056-7

91 Saku K, Zhang B, Noda K, PATROL Trial Investigators. Randomized head-to-head comparison of pitavastatin, atorvastatin, and rosuvastatin for safety and efficacy (quantity and quality of LDL): the PATROL trial. Circ J 2011;75:1493-505. doi:10.1253/circj.CJ-101281

92 Ghia CJ, Panda SK, Khobragade LR, Jha RK. Impact of different starting doses of atorvastatin on reaching target low density lipoprotein cholesterol levels and health related quality of life in dyslipidemic patients. Indian J Physiol Pharmacol 2013;57:293-307.

93 Stender S, Budinski D, Gosho M, Hounslow N. Pitavastatin shows greater lipid-lowering efficacy over 12 weeks than pravastatin in elderly patients with primary hypercholesterolaemia or combined (mixed) dyslipidaemia. Eur J Prev Cardiol 2013;20:40-53 doi:10.1177/2047487312451251

94 Parker BA, Capizzi JA, Grimaldi AS, et al. Effect of statins on skeletal muscle function. Circulation 2013;127:96-103. doi:10.1161/ CIRCULATIONAHA.112.136101

95 Odawara M, Yamazaki T, Kishimoto J, et al. Pitavastatin reduced $\mathrm{C}$-reactive protein without increasing the incidence of diabetes in Japanese individuals with impaired glucose tolerance (J-PREDICT study). Eur Heart I 2014;35:392.

96 Ogawa H, Matsui K, Saito Y, et al. Differences between rosuvastatin and atorvastatin in lipid-lowering action and effect on glucose metabolism in Japanese hypercholesterolemic patients with concurrent diabetes. Lipid-lowering with highly potent statins in hyperlipidemia with type 2 diabetes patients (LISTEN) study -. Circ / 2014:78:2512-5. doi:10.1253/circi.Cl-14-0810

97 Sponseller CA, Morgan RE, Kryzhanovski VA, Campbell SE, Davidson $\mathrm{MH}$. Comparison of the lipid-lowering effects of pitavastatin $4 \mathrm{mg}$ versus pravastatin $40 \mathrm{mg}$ in adults with primary hyperlipidemia or mixed (combined) dyslipidemia: a Phase IV, prospective, US, multicenter, randomized, double-blind, superiority trial. Clin Ther 2014;36:1211-22. doi:10.1016/j.clinthera.2014.06.009

98 Nakagomi A, Shibui T, Kohashi K, et al. Differential Effects of Atorvastatin and Pitavastatin on Inflammation, Insulin Resistance, and the Carotid Intima-Media Thickness in Patients with Dyslipidemia. J Atheroscler Thromb 2015;22:1158-71. doi:10.5551/ jat.29520

99 Patil CY, Baig MS, Doifode SM. Assessing the efficacy and safety of pitavastatin compared to atorvastatin in dyslipidemic patients: a double blind randomized controlled trial. Int / Basic Clin Pharmacol 2016;5:834-40. doi:10.18203/2319-2003. ijbcp20161530.

100 Chen X, Wang S, Lin L, LiY, Zhang H. Drug effect of atorvastatin on middle cerebral atherosclerotic stenosis and high resolution NMR diagnosis. PakJ Pharm Sci 2018;31(3(Special)):1169-73. 
101 Itoh H, Komuro I, Takeuchi M, et al, EMPATHY Investigators. Intensive Treat-to-Target Statin Therapy in High-Risk Japanese Patients With Hypercholesterolemia and Diabetic Retinopathy: Report of a Randomized Study. Diabetes Care 2018;41:1275-84. doi:10.2337/ dc17-2224

102 Toribio M, Fitch KV, Stone L, et al. Assessing statin effects on cardiovascular pathways in HIV using a novel proteomics approach: Analysis of data from INTREPID, a randomized controlled trial. EBioMedicine 2018;35:58-66. doi:10.1016/j.ebiom.2018.08.039

103 Liu M, Liu G, Wang M. Comparison and analysis of the therapeutic effect of different statins in the treatment of atherosclerosis. PakJ Pharm Sci 2018;31(4(Special)):1737-42.

104 Bae JC, Min KW, Kim YH, et al. Efficacy and safety of fixed-dose combination therapy with gemigliptin $(50 \mathrm{mg}$ ) and rosuvastatin compared with monotherapy in patients with type 2 diabetes and dyslipidaemia (BALANCE): A multicentre, randomized, double-blind, controlled, phase 3 trial. Diabetes Obes Metab 2019;21:103-11. doi:10.1111/dom.13491

105 Wang Y, Zhao B, Karlson BW, Wei D, Bots ML, Chen Y. Abstract 11154: Rosuvastatin Slows Progression of Carotid Intima-media Thickness in Low-risk Chinese Individuals With Subclinical Atherosclerosis (the Meteor-china Study). Circulation 2019:140:A11154.

106 Peng $\mathrm{M}$, Dong $\mathrm{H}$, Jiang $\mathrm{X}$, et al. A randomized unblinded trial to compare effects of intensive versus conventional lipidlowering therapy in patients undergoing renal artery stenting. J Cardiol 2019;74:443-50. doi:10.1016/j.jicc.2019.04.010

107 Kitas GD, Nightingale P, Armitage J, Sattar N, Belch JJF, Symmons DP, MTRACE RA Consortium. A Multicenter, Randomized, PlaceboControlled Trial of Atorvastatin for the Primary Prevention of Cardiovascular Events in Patients With Rheumatoid Arthritis. Arthritis Rheumatol 2019;71:1437-49. doi:10.1002/art.40892

108 Moroi M, Nagayama D, Hara F, et al. Outcome of pitavastatin versus atorvastatin therapy in patients with hypercholesterolemia at high risk for atherosclerotic cardiovascular disease. Int J Cardiol 2020;305:139-46. doi:10.1016/j.ijcard.2020.01.006

109 Thongtang N, Piyapromdee J, Tangkittikasem N, Samaithongcharoen K, Srikanchanawat N, Sriussadaporn S. Efficacy and Safety of Switching from Low-Dose Statin to High-Intensity Statin for Primary Prevention in Type 2 Diabetes: A Randomized Controlled Trial. Diabetes Metab Syndr Obes 2020:13:423-31. doi:10.2147/DMSO.S219496

110 Tobert JA, Newman CB. The nocebo effect in the context of statin intolerance. J Clin Lipidol 2016;10:739-47. doi:10.1016/j. jacl.2016.05.002

111 Wood FA, Howard JP, Finegold JA, et al. N-of-1 Trial of a Statin, Placebo, or No Treatment to Assess Side Effects. N Engl J Med 2020:383:2182-4 doi:10.1056/NEJMc2031173

112 Collins R, Reith C, Emberson J, et al. Interpretation of the evidence fo the efficacy and safety of statin therapy. Lancet 2016;388:2532-61. doi:10.1016/S0140-6736(16)31357-5

113 Ganga HV, Slim HB, Thompson PD. A systematic review of statininduced muscle problems in clinical trials. Am Heart J 2014;168:615. doi:10.1016/j.ahj.2014.03.019

114 Law M, Rudnicka AR. Statin safety: a systematic review. Am J Cardiol 2006;97(8A):52C-60C. doi:10.1016/j.amjcard.2005.12.010
115 Baigent C, Blackwell L, Emberson J, et al, Cholesterol Treatment Trialists' (CTT) Collaboration. Efficacy and safety of more intensive lowering of LDL cholesterol: a meta-analysis of data from 170,000 participants in 26 randomised trials. Lancet 2010;376:1670-81. doi:10.1016/S0140-6736(10)61350-5

116 Villani R, Navarese EP, Cavallone F, et al. Risk of Statin-Induced Hypertransaminasemia: A Systematic Review and Meta-Analysis of Randomized Controlled Trials. Mayo Clin Proc Innov Qual Outcomes 2019;3:131-40. doi:10.1016/j.mayocpiqo.2019.01.003

117 Esmeijer K, Dekkers OM, de Fijter JW, Dekker FW, Hoogeveen EK. Effect of different types of statins on kidney function decline and proteinuria: a network meta-analysis. Sci Rep 2019;9:16632 doi:10.1038/s41598-019-53064-X

118 Yu S, Chu Y, Li G, Ren L, Zhang Q, Wu L. Statin Use and the Risk of Cataracts: A Systematic Review and Meta-Analysis. J Am Heart Assoc 2017:6:e004180. doi:10.1161/JAHA.116.004180

119 Sattar N, Preiss D, Murray HM, et al. Statins and risk of incident diabetes: a collaborative meta-analysis of randomised statin trials. Lancet 2010;375:735-42. doi:10.1016/S0140-6736(09)61965-6

120 Hippisley-Cox J, Coupland C. Unintended effects of statins in men and women in England and Wales: population based cohort study using the QResearch database. BMJ 2010;340:c2197. doi:10.1136/bmj. c2197

121 Yebyo HG, Aschmann HE, Puhan MA. Finding the Balance Between Benefits and Harms When Using Statins for Primary Prevention of Cardiovascular Disease: A Modeling Study. Ann Intern Med 2019;170:1-10. doi:10.7326/M18-1279

122 Armitage J. The safety of statins in clinical practice. Lancet 2007;370:1781-90. doi:10.1016/S0140-6736(07)60716-8

123 Rosenson RS, Baker SK, Jacobson TA, Kopecky SL, Parker BA The National Lipid Association's Muscle Safety Expert Panel. An assessment by the Statin Muscle Safety Task Force: 2014 update. J Clin Lipidol 2014:8(Suppl):S58-71. doi:10.1016/j.jacl.2014.03.00

124 Ward NC, Watts GF, Eckel RH. Statin Toxicity. Circ Res 2019;124:32850. doi:10.1161/CIRCRESAHA.118.312782

125 Benjamini Y, Hochberg Y. Controlling the false discovery rate: practical and powerful approach to multiple testing. / R Stat Soc B 1995;57:289-300. doi:10.1111/j.2517-6161.1995.tb02031.x.

126 Hill AB. The environment and disease: association or causation?Proc R Soc Med 1965:58:295-300. doi:10.1177/003591576505800503

127 Warren JB. Translating the dose response into risk and benefit. $\mathrm{Br} J$ Clin Pharmacol 2019:85:2187-93. doi:10.1111/bcp.13949

128 Herrett E, Williamson E, Brack K, et al, StatinWISE Trial Group. Statin treatment and muscle symptoms: series of randomised, placebo controlled n-of-1 trials. BMJ 2021;372:n135. doi:10.1136/bmj. n135

129 Tudor K, Brooks J, Howick J, Fox R, Aveyard P. Tackling statin intolerance with n-of-1 trials (TaSINI) in primary care: protocol for feasibility randomised trial to increase statin adherence. $B M$ Open 2020;10:e033070. doi:10.1136/bmjopen-2019-033070

\section{Web appendix: Supplementary material}

